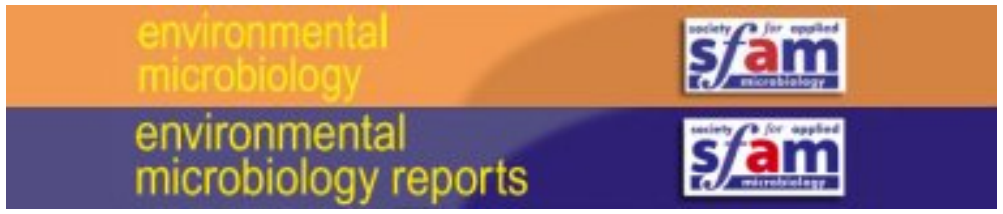

\title{
Dominance of wine Saccharomyces cerevisiae strains over S. kudriavzevii in industrial fermentation competitions is related to an acceleration of nutrient uptake and utilization
}

\begin{tabular}{|r|l|}
\hline Journal: & Environmental Microbiology and Environmental Microbiology Reports \\
\hline Manuscript ID & Draft \\
\hline Journal: & Environmental Microbiology \\
\hline Danuscript Type: & EMI - Research article \\
\hline Complete List of Authors: & $\begin{array}{r}\text { Alonso-del-Real, Javier; Instituto de Agroquímica y Tecnología de los } \\
\text { Alimentos, IATA-CSIC, Food Biotechnology Department } \\
\text { Pérez-Torrado, Roberto; Instituto de Agroquímica y Tecnología de los } \\
\text { Alimentos, IATA-CSIC, Food Biotechnology Department } \\
\text { Querol, Amparo; Instituto de Agroquímica y Tecnología de los Alimentos, } \\
\text { IATA-CSIC, Food Biotechnology Department } \\
\text { Barrio, Eladio; Universitat de Valencia Facultat de Ciencies Biologiques, } \\
\text { Genetics; Instituto de Agroquimica y Tecnologia de Alimentos, } \\
\text { Biotechnology }\end{array}$ \\
\hline Keywords: & $\begin{array}{l}\text { ecological competition, molecular adaptation, <i>Saccharomyces</i> } \\
\text { yeasts, fermentation environment, transcriptomic response, cell-to-cell } \\
\text { contact }\end{array}$ \\
\hline & \\
\hline
\end{tabular}

\section{SCHOLARONE \\ Manuscripts}


1 Dominance of wine Saccharomyces cerevisiae strains over $S$. kudriavzevii in industrial

2 fermentation competitions is related to an acceleration of nutrient uptake and utilization

3 Javier Alonso-del-Real ${ }^{1}$, Roberto Pérez-Torrado ${ }^{1}$, Amparo Querol ${ }^{1}$, Eladio Barrio1,2*

$4 \quad{ }^{1}$ Departamento de Biotecnología de los Alimentos, Grupo de Biología de Sistemas en

5 Levaduras de Interés Biotecnológico, Instituto de Agroquímica y Tecnología de los Alimentos

6 (IATA)-CSIC, Valencia, Spain, ${ }^{2}$ Departament de Genètica, Universitat de València, València,

$7 \quad$ Spain

$8 \quad *$ Corresponding autor: Eladio Barrio

9 Adress: Departamento de Biotecnología de los Alimentos, Grupo de Biología de Sistemas en Levaduras de Interés Biotecnológico, Instituto de Agroquímica y Tecnología de los Alimentos (IATA)-CSIC Avda Catedrático Agustín Escardino Benlloch, 7, 46980 Paterna, Spain.

13 Telephone: +34963900022

14 Fax: +34 963636301

15 Email: Eladio.Barrio@uv.es

Running title: Competition by nutrient uptake acceleration 
Significance Statement

This article is an important contribution to decipher the molecular mechanisms involved in the adaptation to respond to ecological interactions among closely related yeasts species, of interest to understand their growth and survival in fermentation environments.

\section{Summary}

Grape must is a sugar-rich habitat for a complex microbiota which is replaced by

Saccharomyces cerevisiae during the first fermentation stages. Interest on yeast competitive interactions has recently been propelled due to the use of alternative yeasts in the wine industry. The main issue resides in the persistence of these yeasts due to the specific competitive activity of $S$. cerevisiae. To gather deeper knowledge of the molecular mechanisms involved, we performed a comparative transcriptomic analysis during fermentation carried out by a wine $S$. cerevisiae strain and a strain representative of the cryophilic $S$. kudriavzevii, which exhibits high genetic and physiological similarities to $S$. cerevisiae, but also differences of biotechnological interest. In this study, we report that transcriptomic response to the presence of a competitor is stronger in $S$. cerevisiae than in $S$. kudriavzevii. Our results demonstrate that a wine $S$. cerevisiae industrial strain accelerates nutrient uptake and utilization to outcompete the co-inoculated yeast, and that this process requires cell-to-cell contact to occur. Finally, we propose that this competitive phenotype evolved recently, during the adaptation of $S$. cerevisiae to man-manipulated fermentative environments, since a $S$. cerevisiae wild strain with North America oak bark origin showed a remarkable low response to competition. 
Keywords: ecological competition, molecular adaptation, Saccharomyces yeasts, wine fermentation, transcriptomic response, cell-to-cell contact.

\section{Introduction}

In most natural environments, a vast diversity of microorganisms coexists and compete for space and resources. In many aspects, microbial habitats resemble ecological battlegrounds where microorganisms fight until domination or utter destruction of the opponent. Grape must is sugar-rich habitat for a complex microbiota of yeasts and bacteria that are usually replaced by just one or a few Saccharomyces cerevisiae strains after the first stages of wine fermentation (Querol et al., 1994; Fleet, 2003). In this paper, we understand the concept of dominance as the phenomenon that is observed in mixed microbial populations when one individual (strain) is outnumbered by another (Pérez-Torrado et al., 2017).

Competitive interactions between $S$. cerevisiae and other naturally present microorganisms in wine must, mostly non-Saccharomyces yeast, have been the subject of diverse studies (Fleet, 2003; Bagheri et al., 2016; Ciani et al., 2016). This interest has recently been propelled due to the fact that, in the last years, the use of alternative yeasts in winemaking has become a widespread trend to respond to the new demands of the wine industry (Jolly et al., 2014; Pérez-Torrado et al., 2017). These demands come from, first, the effect of global warming on vines, which produces an uncoupling of sugar content and phenolic maturity in grapes resulting in higher ethanol yields; and two, an increasing market demanding wines with lower ethanol content and with diverse flavours and aroma.

S. cerevisiae yeasts are characterized by their high capability to ferment simple sugars into ethanol even in the presence of oxygen, Crabtree (1928) effect. Although alcohol fermentation is energetically much less efficient than aerobic respiration, it provides with a 
selective advantage to these yeasts to outcompete other microorganisms: sugar resources are consumed faster and the ethanol produced during fermentation (Goddard, 2008), as well as higher levels of heat and $\mathrm{CO}_{2}$, can be harmful or less tolerated by their competitors (Piskur and Langkjaer, 2004; Piškur et al., 2006; Conant and Wolfe, 2007; Merico et al., 2007; Hagman et al., 2013; Williams et al., 2015). Also, nitrogen source consumption and biomass production are more efficient in S. cerevisiae (Monteiro and Bisson, 1991; Andorrà et al., 2012). Therefore, a more efficient nutrient uptake seems to be one of the most important factors for S. cerevisiae dominance.

Strikingly, some studies suggested a secondary or irrelevant role for ethanol as a selective factor, and pointed to other factors as determinant of the competition outcome. Some authors proposed a relevant role to the production and release of toxic peptides by $S$. cerevisiae, such as those derived from glyceraldehyde 3-phosphate dehydrogenase (GAPD) (Pérez-Nevado et al., 2006; Albergaria et al., 2010; Branco et al., 2014). Temperature, as already mentioned, has also been proven to be highly influential on competitions (Goddard, 2008; Arroyo-López et al., 2011). In fact, fermentations under low temperature conditions can benefit the competition capability of cryophilic Saccharomyces yeasts, such as S. eubayanus, $S$. kudriavzevii and $S$. uvarum, which can coexist with $S$. cerevisiae until the end of mixedculture fermentations at low temperatures (Alonso-del-Real, et al., 2017).

Strains belonging to these three cryophilic Saccharomyces species were already proposed as promising starters for wine fermentations (Arroyo-López et al., 2010; Peris et al., 2016; Alonso-del-Real et al., 2017; Henriques et al., 2018). They exhibit physiological properties that are especially relevant during the winemaking process, such as their good performance in fermentations at low temperatures, resulting in wines with lower alcohol and higher glycerol contents (Varela et al., 2016; Pérez-Torrado et al., 2017), as well as the production of larger 
and diverse amounts of aromatic compounds (Gamero et al., 2013; Stribny et al., 2015). S. kudriavzevii, as a member of the Saccharomyces genus, exhibits a higher genetic and, physiological similarity with $S$. cerevisiae, as well as species-specific differences (ArroyoLópez et al., 2010; Gamero et al., 2013; Stribny et al., 2015, 2016; Peris et al., 2016), including a better cold adaptation (Tronchoni et al., 2014). In previous studies, we also characterized $S$. kudriavzevii behaviour during competition with S. cerevisiae (Arroyo-López et al., 2011; Alonso-del-Real, Lairón-Peris, et al., 2017). However, the main problem of their use, as occurs with most alternative yeast, resides in their implantation and persistence during wine fermentations. Alonso del Real et al. (2017) showed that S. cerevisiae is not affected by most temperature conditions when competing with $S$. kudriavzevii during fermentation, except at very low temperatures, i.e. $8^{\circ} \mathrm{C}$. It is interesting to note that low temperature fermentations, in which $S$. kudriavzevii coexist with $S$. cerevisiae in high proportions (close to 50\%), produce wines containing less ethanol and higher amounts of glycerol than wine fermentations conducted only by $S$. cerevisiae, however, higher temperatures result in domination of the culture by $S$. cerevisiae, with very low proportion of $S$. kudriavzevii.

Factors of presumable relevance in the domination phenomenon are cell-to-cell contacts and interactions, as assessed in previous studies (Nissen and Arneborg, 2003; Renault et al., 2013; Kemsawasd et al., 2015; Wang et al., 2015). Moreover, quorum sensing mediated mechanisms have been proposed as taking place during competition (Rivero et al., 2015). In fact, competitor cells have to be in close proximity for an effective response to competition (Arneborg et al., 2005; Pérez-Torrado et al., 2017). However, little information is available about the recognition mechanisms and specific responses of Saccharomyces yeasts to the presence of a competitor. This information could be of especial relevance to understand yeast 
interactions during wine fermentation because they potentially affect yeast metabolism and growth, and thus alter the final characteristics and quality of wine.

Transcriptomic analyses have the potential to unveil the cell response to competition at the molecular level. The gene expression program of $S$. cerevisiae during wine fermentation has been profiled in previous studies (Rossignol et al., 2003; Zuzuarregui et al., 2006; Novo et al., 2013; Barbosa et al., 2015; Mendes et al., 2017). Previous studies using this approach regarding competition focused in the interactions among $S$. cerevisiae and bacteria or far distant non-Saccharomyces yeasts. More recently, the use of RNAseq allowed to study differential expression not only in $S$. cerevisiae, but also in the co-inoculated competitor Torulaspora delbrueckii yeast, observing an activation of both growth and carbon metabolism, which seemed to occur earlier in S. cerevisiae (Tronchoni et al., 2017). These authors observed expression activation of genes related to sugar and nitrogen metabolism under aerobic conditions when S. cerevisiae was cultured with other non-Saccharomyces yeast (Curiel et al., 2017).

In the present work, we performed a transcriptomic analysis during wine fermentations coinoculated with a wine $S$. cerevisiae strain and a strain representative of the closely related species S. kudriavzevii to shed light into the molecular mechanisms involved in the interaction between these two species that could be responsible of the dominance of $S$. cerevisiae in fermentations. Also, we included a S. cerevisiae strain isolated from oak tree bark in North America in order to check for this trait to be linked to the origin of a given population.

\section{Results}

Analysis of differential gene expression during competition between $S$. cerevisiae and $S$. kudriavzevii 
The aim of this work is to elucidate the molecular response behind the dominance of $S$. cerevisiae when competing against the yeast of potential industrial interest $S$. kudriavzevii during wine fermentations. A transcriptome analysis of the wine yeast S. cerevisiae T73 in fermentation at $12{ }^{\circ} \mathrm{C}$ and $20^{\circ} \mathrm{C}$, with and without the presence of a Saccharomyces wild yeast, S. kudriavzevii CR85, was performed. Samples were collected at three different fermentation stages: early exponential phase (EEP), late exponential phase (LEP) and stationary phase (SP). These three time points at the very beginning of fermentation were selected based on previous results that showed that after these stages cell populations remained stable at the same proportions (Figure S1). In addition, the same experiment, but this time using a S. cerevisiae strain isolated from oak bark, S. cerevisiae strain YPS128 and S. kudriavzevii CR85, was performed with the goal of elucidating whether the competition effect is associated at species or strain levels.

The defined variables in the differential expression analysis were time, temperature, culture (single or co-inoculated) and species. PCA of our samples showed that $59 \%$ of variance corresponded to PCA component 1, which could be practically identified with the variable species itself (Figure S2). Even when samples were clustered just according to genes exclusively affected by the variable culture, first branch unequivocally separated $S$. cerevisiae and S. kudriavzevii samples (Figure S3). Although gene expression differences among Saccharomyces species are very interesting, the main objective of the present study is to determine the effect of the species competition on gene expression. For this reason, we decided to keep all of the available genes for each species. Thus, two species-specific datasets were used for the subsequent analyses. 
155 A PCA of the $S$. cerevisiae dataset showed that samples grouped mainly according to the variable time, meaning that the phase of fermentation was the main factor for sample variance. The variable culture accounted for less sample variance, that is, for lower levels of differential expression (Figure 1). In the case of $S$. kudriavzevii, there was an overlap among the different fermentation stages; $20^{\circ} \mathrm{C}$ LEP and $12^{\circ} \mathrm{C}$ LEP samples cluster with $20^{\circ} \mathrm{C}$ EEP samples, and $20^{\circ} \mathrm{C} \mathrm{SP}$ monoculture samples, respectively. In comparison to $S$. kudriavzevii, $S$. cerevisiae's variable culture seems to provide a higher sample variance. Differential gene expression analysis between mono and co-culture was carried out by contrast analysis for each species at each temperature and time point to avoid masking effect of these variables.

Interestingly, $S$. cerevisiae showed a stronger transcriptional response to competition during the EEP, higher at $12{ }^{\circ} \mathrm{C}$ than at $20^{\circ} \mathrm{C}$ (Figure. 2a). This response decreases during the following stages at both temperatures, but faster at $20^{\circ} \mathrm{C}$. On the contrary, S. kudriavzevii presented during EEP a clearly higher response at $20^{\circ} \mathrm{C}$ than at $12^{\circ} \mathrm{C}$, but, as the fermentation progresses, the number of differentially expressed genes increase at both temperatures, becoming very similar during LEP and identical at SP. These results are in agreement with the growth dynamics exhibited by both species in co-cultures compared to monocultures. $S$. kudriavzevii cell density was severely affected at SP, whilst $S$. cerevisiae remained practically unaltered at this stage (Figure $\mathbf{2 b}$ ).

A first general overview of the differential expression analysis highlights a higher expression remodelling in S. cerevisiae T73 at EEP, which points to a detection of the competitor at the first stages of fermentation, and a response that might be more efficient in $S$. cerevisiae under these conditions. In the subsequent stages, the unsuccessful S. kudriavzevii showed a 
noticeable stress response due to its difficulties in competition culture, which is assessed 178 below.

a) Differential expression in S. cerevisiae at EEP during competition

Gene expression modulation in response to competition was already noticeable at EEP. $S$. cerevisiae showed greater differential gene expression between monoculture and co-culture samples at $12^{\circ} \mathrm{C}$ than at $20^{\circ} \mathrm{C}$ (Figure 2a). At $20^{\circ} \mathrm{C}, 680$ genes were overexpressed in coculture, and 658 genes were repressed (p-value $<0.05$, Table S2). At $12^{\circ} \mathrm{C}$, of the 3518 differentially expressed genes in co-culture, 1874 were overexpressed and 1644 repressed

(Table S2). Assessing the function of those genes by functional categories enrichment analysis, processes related to metabolism and cell growth were found at both temperatures

(Table S1). With respect to repressed genes in co-culture, at $12^{\circ} \mathrm{C}$ we found many categories related to transcription, ribosome synthesis and translation (Table S1).

We found 198 upregulated and 79 downregulated genes in common at both temperatures, stage of fermentation. These genes were also classified into functional categories and clustered according to their expression level for S. cerevisiae at EEP (Figure 3a). One of the most relevant categories is gene expression regulation, with a high number of genes involved translation regulation. Among the repressed genes, those encoding mitochondrial ribosomal proteins are the most represented class. This agrees with the finding of upregulated genes related to respiration. This change in metabolism is coupled with an upregulation of mitosis and cell cycle progression, and the repression of telomere maintenance genes, which points to 
a faster cell proliferation. In addition, multiple stress response genes were also upregulated, especially those involved in oxidative stress and heavy metal detoxification. Also, glutathione seemed to be synthetized at EEP as well as a relevant set of $A B C$ transporters involved in multidrug detoxification are also overexpressed.

Genes involved in mating pheromone response, as well as some meiosis activating genes, were also overexpressed (Figure 3a). Genes involved in endocytosis, protein trafficking, protein degradation, and UPR response were among the upregulated genes. The overexpression of $G A T 1$ and $A P G 1$, genes encoding general amino acid transporters, amino acid biosynthesis and TOR signalling pathway genes, are considered as indicative of an acceleration of the nitrogen uptake and metabolism. In addition, iron and zinc uptake and homeostasis genes were also overexpressed. As for carbon metabolism, glycerol, ergosterol, long fatty acid, pentose phosphate pathway and acetate synthesis seemed to be favoured, with an important role of plasma membrane regulation.

To check which transcription factors were regulating gene expression during yeast competition, we used the contrast function of DESeq2 package to generate an expression dataset similar to the previous one, but considering both temperatures. We manually assigned $p$-value 0 to the culture-dependent genes set and $p$-value 1 to the rest of genes. Then, this dataset was loaded into PheNetic (De Maeyer et al., 2015) web tool, which uses publicly available interactomics data to create networks from a given expression dataset, revealing possible master regulators and cellular processes relevant for the sample. In this case, the analysis determined Cin5p (YOR028C), Phd1p (YKL043W) and Spt23p (YKL020C) as the central transcription factors, which are involved in response to external stimulus and are known to recruit the general repressor Tuplp to certain promoters (Hanlon et al., 2011) (Fig. 3b). Other transcription factors known to be involved in external stimulus response were 
225 Yrm1p (YOR172W) and Cbf1p (YJR060W). In addition, Abflp (YKL112W), involved in

226

227 vesicle trafficking; Sda1p (YOR344C), required for cytoskeleton organization and ribosome biogenesis; and Ihflp (YLR223C), which regulates ribosomal genes transcription and is regulated by TOR signalling pathway, constituted the main nodes in the interaction network.

The typical gene expression along the fermentation for the differentially expressed genes at EEP is the dissipation of this response in the subsequent stages, as in MIPI (Figure 3C). However, we could find only one gene, HSP30, that was kept downregulated in the co-culture with respect to the single culture, especially at $12{ }^{\circ} \mathrm{C}$ (Figure 3C).

b) Differential expression in S. cerevisiae at LEP and SP during competition At LEP, we found important differences with respect to temperature and at the species level. Regarding the number of differentially expressed genes, S. cerevisiae showed 29 at $20^{\circ} \mathrm{C}$ and 1388 at $12{ }^{\circ} \mathrm{C}$ (Figure 2). No significant enriched functional categories were obtained for the $20^{\circ} \mathrm{C}$ condition. However, at $12^{\circ} \mathrm{C}$, there was a clear response of membrane and cell wall remodelling. (Table S1). Also, several genes involved in iron homeostasis were overexpressed in co-culture (Table S2). 55 differentially expressed genes were found at SP, which are involved in meiotic phase entrance, translation repression, and response to DNA replication stress (Table $\mathbf{S 2}$ ).

c) Differential Expression in S. kudriavzevii during competition

Comparatively to $S$. cerevisiae, S. kudriavzevii showed at EEP a lower response to the presence of S. cerevisiae, with 75 and 980 hits at $12^{\circ} \mathrm{C}$ and $20^{\circ} \mathrm{C}$, respectively. Differential gene expression increased dramatically in the next stages as can be appreciated in figure 2. At LEP, repressed genes at $20^{\circ} \mathrm{C}$ and $12^{\circ} \mathrm{C}$ arose to 1749 and 1043 , respectively. Finally, a huge remodelling of expression in $S$. kudriavzevii took place at SP in the co-cultures with $\sim 2,500$ 
hits for both temperatures. All the genes and enriched GO terms can be explored in the supplementary material of this paper (Tables S1 and S3). However, we included a summary of the main enriched functional categories for S. kudriavzevii in Table 1. At EEP, there is already a slight response to the presence of $S$. cerevisiae. But, in concordance with the higher number of genes, the response becomes much higher in the next stages, with genes and related to stress response, nutrient homeostasis, and metabolism remodelling.

d) Identification of transcription factors responsible of the differential gene expression during competition

Datasets of differentially expressed genes for every time point, temperature and strain were analysed with Phenetics (Table 2). At a first glimpse, we could observe the logical lack of central transcription factors for S. kudriavzevii during EEP at $12{ }^{\circ} \mathrm{C}$ and for S. cerevisiae during LEP and SP at $20{ }^{\circ} \mathrm{C}$ given the low number of genes in these datasets. Nonetheless, Cin5p, Phd1p and its paralog Sok2p, Mga1p, and Msn4p appeared as the most common factors for all the conditions.

\section{Nutrient consumption during competition}

One of the most important results of the comparative transcriptome analysis is that competition favours the expression of genes related to nutrient uptake and cell division, which, in the case of the wine $S$. cerevisiae strain, occur from the first stages of the coinoculated fermentation. To determine whether nutrient uptake is actually playing a key role in the imposition of $S$. cerevisiae or not, we compared the consumption profiles of nitrogen and carbon sources in single vs. co-inoculated fermentations.
a) Nitrogen uptake 
Nitrogen source concentrations present in the medium (amino acids and ammonium) were measured by HPLC after 12 hours and 24 hours in the single and co-inoculated fermentations at $20^{\circ} \mathrm{C}$. After 12 hours, differences in consumption are almost inexistent among the samples, however, $S$. cerevisiae had consumed after the first 24 h (LEP) a larger amount of most nitrogen sources in the medium than S. kudriavzevii with the clear exception of tryptophan (Figure S4, Figure 4). An interesting outcome of this analysis is the different pattern of nitrogen source preferences exhibited by the wine $S$. cerevisiae and the wild $S$. kudriavzevii. This way, there are clearly significant differences in the consumption of histidine, which is consumed by $S$. cerevisiae but not by $S$. kudriavzevii, tryptophan, one of the preferred amino acids for S. kudriavzevii but one of the less consumed by S. cerevisiae, and ammonium which is more preferable for $S$. cerevisiae than for S. kudriavzevii. Interestingly, nitrogen source consumption in co-inoculated cultures showed a very similar profile to that exhibited by $S$. cerevisiae in single cultures for all sources, including those that are differentially preferred. This is indicative that wine $S$. cerevisiae determines the amino acid uptake pattern because is faster consuming those nutrients present in the medium. This allows $S$. cerevisiae to outcompete S. kudriavzevii and dominate wine fermentations.

b) Sugar consumption

In a previous study (Tronchoni et al., 2009), we observed a different patterns of fructose and glucose consumption during fermentation in different Saccharomyces strains, including the two strains used in this study. Therefore, fructose and glucose concentrations were measured by HPLC along fermentation to determine if the carbon source uptake rate is also accelerated during competence. Consumption kinetics of these compounds at $12{ }^{\circ} \mathrm{C}$ and $20^{\circ} \mathrm{C}$ fits to a non-linear model (Figure 5). In co-inoculated fermentations at $12^{\circ} \mathrm{C}$, fructose consumption was clearly faster than in monocultures, which was statistically verified by the time necessary 
to consume $90 \%$ of the corresponding carbon source (Table 3). Although differences are not statistically significant in the case of glucose consumption at $12^{\circ} \mathrm{C}$, a similar trend is observed. However, at $20^{\circ} \mathrm{C}$ there were no differences in the fructose consumption between S. cerevisiae monoculture and the competition, but the difference is significant with respect to the single culture of S. kudriavzevii. Again, although differences are not statistically significant with respect to glucose consumption at $12^{\circ} \mathrm{C}$, consumption in the single culture of S. cerevisiae and in the competition are identical and different from consumption in $S$. kudriavzevii monoculture. S. kudriavzevii gene expression did not suffer major changes at this stage, so this sugar consumption acceleration was more likely due to $S$. cerevisiae activity.

\section{Importance of cell contact in competitive fitness}

As important part of the competitive response mechanism, we wanted to check whether direct cell-to-cell contact is necessary to trigger this process, we performed a set of fermentations in which a dialysis membrane was used to compartmentalize the cultures to avoid cell-to-cell contact. The intrinsic growth rate ( $r$ ) parameter was calculated as a metric for fitness. Interestingly, whereas fermentations in which competitors were separated by membranes showed very similar fitness, co-cultures in the same compartment presented significantly lower values than the single cultures, with $\mathrm{p}$-values of $2.32 \mathrm{E}^{-4}$ for $S$. kudriavzevii and $2.01 \mathrm{E}^{-3}$ for $S$. cerevisiae (Figure 6, Sk_co_contact and Sc_co_contact bars). This effect was clearer in S. kudriavzevii, agreeing with the stress response observed in competition with $S$. cerevisiae T73. These results indicate that cell-to-cell contact is a necessary, or at least important, condition for wine yeast to overcome their competitors.

\section{Is the response to competition with $S$. kudriavzevii similar in wine and in wild $S$.} cerevisiae strains? 
To elucidate whether the response to competition is identical or different between wine and wild $S$. cerevisiae strains, we performed a similar study of the response to competition between S. kudriavzevii and a wild S. cerevisiae strain, YPS128, isolated from a Pennsylvanian Oak tree (Sniegowski et al., 2002). All fermentations were conducted at $20^{\circ} \mathrm{C}$, a temperature at which both strains coexist (Alonso-del-Real et al., 2017).

Regarding the dynamics of differential expression between S. cerevisiae YPS128 in cocultures with respect to monocultures, LEP was the only phase when S. cerevisiae YPS128 showed a certain level of differential gene expression, with 65 overexpressed genes and 2 repressed genes for cultures in competition (Figure 7a, Table S4). This suggests that faster nutrient uptake did not take place in co-fermentation using a wild strain of $S$. cerevisiae as we had observed with the wine strain T73, which points to an important adaptation to fermentation by $S$. cerevisiae wine strains. This was confirmed by the HPLC analysis on sugar composition during the competition (Table 3), and agrees with the lack of growth rate acceleration in co-cultures during competition (Figure $\mathbf{7 b}$ ), in contrast to the acceleration observed in T73 co-cultures (Figure 2b).

On the contrary, S. kudriavzevii level of response follows a similar pattern to that observed in its co-culture with the wine strain T73 (Figure 7a). At EEP, overexpressed genes were related to sporulation, and others had a variety of functions such as glucose transport or nitrogen assimilation utilization (Table S6). There was an important gene expression regulation at LEP. The 494 overexpressed genes generated enriched GO terms ammonium transport, fatty acid metabolic process, response to stress, protein refolding, (Table S5). In addition, the MIPS categories metabolism of nonprotein amino acids, oxidative stress response, $C 4$ dicarboxylate transport and cell periphery were found (Table S5). For the 213 repressed genes, every GO term enrichment result is related to vesicle transport, such as ER to Golgi 
transport or membrane (Table S5). Interestingly, a situation of stress and metabolism remodelling was taking place at this stage, despite the slight differential transcriptome regulation of S. cerevisiae YPS128. Finally, at SP stage, a huge transcriptome regulation change was observed, with around 1,500 overexpressed genes and 1,200 repressed genes in co-culture (Table S6). Involved processes showed nutrient limitation and metabolic profile remodelling. Processes that appeared to be diminished are mitosis, cell cycle, mitochondrial translation, protein transport and ribosomal proteins (Table S5). Thus, nutrients uptake and homeostasis together with response to toxicity seemed to be the main cell functions supported, reflecting a harsh situation for S. kudriavzevii in co-culture with respect to single culture.

Our results are compatible with a situation in which $S$. cerevisiae YPS128 did not change its behaviour during competition, and hence, is not able to reduce $S$. kudriavzevii up to the same extent as the industrial strain.

Furthermore, we showed above that cell-to-cell contact is important in the competition between $S$. kudriavzevii and a wine $S$. cerevisiae strain. However, when we assessed the performance of $S$. cerevisiae YPS128 in a compartmentalized fermentation, no significant differences were observed either in $S$. cerevisiae or in $S$. kudriavzevii fitness when cell contact is allowed or not (Figure 8, Sk_co_contact and Sc_co_contact bars). This result suggests that efficient competitive response in wine fermentation is a strain dependent trait in S. cerevisiae, and likely specific of the highly competitive wine yeasts. It also agrees with the lower differential gene expression in the wild strain compared to the wine one.

\section{Discussion}


Crabtree effect is a common to all Saccharomyces species ecological strategy and could explain how Saccharomyces yeasts could outcompete bacteria and non-Saccharomyces yeasts, but not how the ancestor of wine $S$. cerevisiae successfully occupied and outcompeted other Saccharomyces yeasts in the new ecological niche found in the crushed grape berries gathered by humans to produce the first fermented beverages. The simplest answer is that these yeasts have since then been exposed to selective pressures due to fluctuating stresses occurring during wine fermentation, such as osmotic stress due to high sugar concentrations, anaerobic stress, acid stress, nutrient limitations, ethanol toxicity or sulphite toxicity (Querol et al., 2003). As a result of this unaware domestication, wine $S$. cerevisiae yeasts are better adapted to this environment than other Saccharomyces yeasts (Arroyo-López et al., 2010; Navarro-Tapia et al., 2016). This is supported by the fact that wine $S$. cerevisiae yeasts exhibit differential adaptive traits (Marsit and Dequin, 2015) and conform a genetically differentiated population (Fay and Benavides, 2005; Liti et al., 2009; Almeida et al., 2015).

In the last years, several studies tried to dissect in more detail yeast competition by using bottom-up approaches based on co-culturing different strain combinations in the laboratory, mainly wine $S$. cerevisiae and non-Saccharomyces yeasts due to their winemaking applications. This way, different possible, and up to some point, compatible mechanisms or phenotypes relevant for competitive interactions between $S$. cerevisiae and non-

Saccharomyces have been identified. Although, in some studies, cell-to-cell contact seemed to be unimportant in the competitive phenomenon, which would depend mostly on nutrient depletion or toxic metabolite release (Wang et al., 2015), others indicated that interactions were clearly dependent on a cell-to-cell contact or a close proximity of the competitors (Nissen and Arneborg, 2003; Renault et al., 2013). In some studies, cell-to-cell contacts mediated a killer effect of the constitutive accumulation of GADP-derived peptides in the cell 
wall of S. cerevisiae, which affects viability of non-Saccharomyces yeasts (Kemsawasd et al., 2015; Branco et al., 2018). Also, cell proximity was also required for a sulphite-sensitive $S$. cerevisiae strain to be affected by the toxic effect of the sulphite efflux produced by a tolerant strain (Pérez-Torrado et al., 2017). In some cases, competition can be passive, such as the constitutive production of toxic compounds (Branco et al., 2016), but in other is regulated as a specific response to the presence of competitors. Active response to competitors can be mediated by indirect effector molecules (quorum-sensing signalling) or by cell-to-cell contact. As an example of the former, Rivero et al (2015) proposed that the detection of a competitor S. cerevisiae strain by a winery dominant $S$. cerevisiae strain was mediated by the altruistic autolysis and release of Hsp12p, which acts as a quorum sensing signal to stimulate killer activity and auto protection, encoded by the $P A U$ genes. As an example of the latter, Perrone et al. (2013) suggested that dominant response of a strain only occurs when there is a detection of the competitor mediated by cell-to-cell contact.

In the present study, we also reported how a wine $S$. cerevisiae strain was able to dominate the fermentation niche after the detection of the competitor mediated by cell-to-cell contact. As a response to competition, T73 extensively reprogrammed gene expression, which lead to a more efficient nutrient consumption and apparent growth anticipation. This behaviour had been previously observed in the case of competitions against bacteria and non-Saccharomyces yeast (Tronchoni et al., 2017). This seems to be linked to the modification of the plasma membrane composition. Ergosterol modifies the fluidity of the yeast membrane, which allows a more efficient activity of membrane transporters and increases tolerance to ethanol, characteristics related with a higher fermentation performance. According to the transcription factors found to be most likely the central nodes in this genetic acclimation, stress like response also seems to take place during competition. However, once $S$. cerevisiae 
accelerated nutrient uptake and accumulation in the first fermentation stages, the expression remodelling response decreased in the subsequent periods. Interestingly, HSP30 was found to be the only gene downregulated in the three different time points. Hsp30p is a chaperone involved in the correct folding of certain membrane proteins, among which Pmp1p is one of the most important. Pmplp is a basic element in intracellular $\mathrm{pH}$ regulation and is directly involved in processes such as stress response (Dong et al., 2017) and aging. Pmp1p accumulates in the plasmatic membrane after every budding event, and its accumulation determines cell aging by impeding further cell divisions (Henderson et al., 2014). Thus, the repression of HSP30 expression would imply defects in Pmplp folding, which could constitute a mechanism for cell division deregulation.

S. kudriavzevii also exhibits a response to competition in which nutrients uptake seems to be important. High affinity sugar transporters were overexpressed in a moment when sugar was still at elevated concentration in the medium, as well as the oligopeptide transporter coding gene $O P T 1$, which have been recently identified among the upregulated genes of wine $S$. cerevisiae in co-culture with Oenococcus oeni (Rossouw et al., 2012). Oligopeptides transporters activation could be a mechanism for nitrogen resources increased acquisition (Marsit et al., 2016). Moreover, the nodes obtained for the control of gene expression in response to competition at $20{ }^{\circ} \mathrm{C}$ are very similar to those found for $S$. cerevisiae, pointing to a similar response which would be temperature dependent. However, this response in $S$. kudriavzevii is delayed and weaker than in S. cerevisiae, which acquires and accumulates nutrients in a faster way, and hence, this response could be activated as a consequence of the progressive reduction of nutrients available in the medium, especially limiting nitrogen sources, rather than by the presence of a competitor. In fact, when $S$. kudriavzevii detected the 
nutrient depletion caused by $S$. cerevisiae, increasingly triggers stress response mechanisms to cope with it in the later stages of fermentation.

Regarding the regulation of the expression, we identified several central transcription factors present in most conditions. The most frequently found was CIN5. Cin5p belongs to the Yap protein family, and is involved in protein degradation (Sollner et al., 2009), salt tolerance (Ni et al., 2009), and diverse stress response (Nevitt et al., 2004). Noteworthy, its paralog Yap6p, also involved in salt tolerance (Mendizabal et al., 1998) is present among the central factors in S. kudriavzevii during SP at $20^{\circ} \mathrm{C}$. Phd1p and Sok2p regulate pseudohyphal growth in opposite ways, being Sok2p a repressor of the enhancer Phd1p. Swi5p, another of the transcription regulators found, is also involved in this process (Pan and Heitman, 2000). Pseudohyphal growth occurs under nitrogen limitation conditions, mediated by the heterodimers Tec1p and Ste12p (Gavrias et al., 1996), also present in our analysis. Cin5p, Yap6p, and Phd1p regulate expression under changing environmental conditions, such as stress by nutrient limitation, by recruiting the transcription repressor Tup1p (Hanlon et al., 2011). Mga1p has also been related to heat shock response and pseudohyphal growth. The general stress response transcription factors Msn2p and Msn4p were also present in almost all datasets indicating cells are responding to stress.

For the present study, we used a wine $S$. cerevisiae strain because the main goal was to understand the mechanisms that allow a wine strain to outcompete strains from another Saccharomyces species not present in wine. In fact, the wine strain T73 was selected for commercialization as a dry yeast due to its good performance during wine fermentation and is widely used at industrial level (Querol et al., 1992). However, despite other S. cerevisiae strains isolated from diverse fermentative and wild environment are variable with respect to fermentation capability, osmotic and ethanol tolerances, they generally show better 

and, depending on the fermentation temperature, they can outcompete them (Alonso-del-Real, et al., 2017). Here, we report two different competitive phenotypes in S. cerevisiae. We hypothesize that the wine strain exhibits a strong response including enhanced nutrient uptake abilities based on an active conditional response to the presence of the competitor $S$.

kudriavzevii. These results are congruent with the observation mentioned above that $S$. cerevisiae $\mathrm{T} 73$ response to competition consisted on a deep gene expression remodelling which would switch the cells into a more actively nutrient uptaking state. On the contrary, the wild isolate YPS128 showed a passive constitutive response to the same competitor. These results are of especial relevance from an evolutionary point of view because they indicate that wine strains acquired new active mechanisms of response to competition during their adaptation to fermentation environments, such as the general acceleration of nutrient uptake and accumulation during competition. This mechanisms is compatible with the acquisition of other specific mechanisms based on the production of toxic compounds (Pérez-Torrado, et al., 2017). For example, sulphite production is used by sulphite-tolerant strains, a trait that has appeared at least twice in wine S. cerevisiae strains (Pérez-Ortín et al., 2002; Zimmer et al., 2014).

As mentioned, the active response of the wine $S$. cerevisiae strain to competition depends of a direct contact or a close proximity to the competitor S. kudriavzevii. However, additional research is required to unveil the mechanisms triggering this response. The recent description of the $S$. cerevisiae pangenome based on 1,011 genomes (Peter et al., 2018) reported 2,856 variable (present/absent) ORFs, being cell-cell interaction one of the most enriched functional categories. Indeed, some of the genes we found as differentially expressed in competition, which functions remain unknown, could be specifically involved in microbial interactions. 
482 Among them, the $F L O$ gene family could be a clear candidate as the main function of these

483

484

485

486

487

488

489

490

491

492

493

494

495

496

497

498

499

500

501

502

503

504

505

genes is self-recognition and flocculation interaction with other cells (Goossens et al., 2015).

In fact, a study in which FLO1, FLO5, FLO9 and FLO10 expression was controlled in cocultures of S. cerevisiae and several non-Saccharomyces yeast, aggregation-flocculation and yeast competitive fitness varied depending on the competitor species and the overexpressed flocculin, which implies a species- or strain-specific mechanism of cell-to-cell interaction (Rossouw et al., 2015). Whatever the role of the FLO gene family is, the recognition mechanism involved in the competition interactions is not only species dependent, but also strain dependent, as the transcriptomic response in the wine $S$. cerevisiae T73 is completely different to that observed in the wild S. cerevisiae YPS128.

Transcriptomic analyses are broadly considered a good first approach to understanding the state of a given cell population or its response to a stimulus. In fact, its use is becoming wider in the study of the physiology of Saccharomyces from industrial or other origins, especially the species Saccharomyces cerevisiae (Carvalho-Netto et al., 2015; Sardi et al., 2016; Nielsen et al., 2017; Yang et al., 2017; Zhang et al., 2018). However different authors had demonstrated a notable lack of correlation with proteomics or metabolomics data that cannot be diminished (Gygi et al., 1999; Chen et al., 2002; Pascal et al., 2008; Ghazalpour et al., 2011; Yeung, 2011). Thus, we tried to confirm the most relevant features of the extensive response observed by physiological or metabolic experiences. Moreover, we intend to conduct further research to obtain a more accurate and informed prediction on the nature of interactions in the wine microbiota; $i . e$. whether the recognition of a strange species could depend on cell wall proteins physical interactions. This can have many important implications in the management and design of the inoculation process to improve wine fermentations according to the producer's and consumer's demands. 
506

507

508

509

510

511

512

513

514

515

516

517

518

519

520

521

522

523

524

525

526

527

528

\section{Experimental Procedures}

\section{Yeast Strains}

Three different Saccharomyces strains were used in our experiments. We chose a commercial strain, T73 (Lalvin T73 from Lallemand Montreal, Canada), as a typical representative of a wine S. cerevisiae yeast. We also included YPS128, isolated from Pennsylvania woodlands, as a representative of a wild $S$. cerevisiae strain. Finally, for $S$. kudriavzevii, we chose strain CR85, a wild isolate from oak tree bark in Agudo, Ciudad Real, Spain, characterized by being closely related to the parent of the wine hybrids $S$. cerevisiae $x$ S. kudriavzevii and by its good performance in microvinification (Peris et al., 2016). Complete genome sequences are available for these three strains (unpublished results from our laboratory and GenBank BioProject ref. PRJEB7245 and PRJNA480800).

\section{Synthetic Must Fermentation}

Synthetic must (SM, Rossignol et al., 2003) was used in microvinification experiments, with $100 \mathrm{~g} / \mathrm{L}$ glucose and $100 \mathrm{~g} / \mathrm{L}$ fructose. GPY medium (2\% glucose, $2 \%$ peptone, $1 \%$ yeast extract) was used for overnight growth of precultures.

Fermentations were performed with single cultures of $S$. cerevisiae T73, S. cerevisiae YPS128, and S. kudriavzevii CR85 and cocultures of equal proportions of $S$. cerevisiae T73 and S. kudriavzevii CR85, and S. cerevisiae YPS128 and S. kudriavzevii CR85. All fermentations were performed in triplicate in $250 \mathrm{~mL}$ flasks with screw caps that contained $200 \mathrm{~mL}$ of SM.

Overnight precultures were grown in GPY medium at $25^{\circ} \mathrm{C}$ and used to inoculate synthetic musts with an initial concentration of $10^{6}$ cells $/ \mathrm{mL}$. Fermentations were incubated at two temperatures $\left(12^{\circ} \mathrm{C}\right.$ and $\left.20^{\circ} \mathrm{C}\right)$ with agitation at $100 \mathrm{rpm}$. 


\section{RNA Sequencing}

Sample collection for gene expression profiling was done at three different fermentation times: early exponential phase (EEP), late exponential phase (LEP) and stationary phase (SP). These correspond to 24,90 and $135 \mathrm{~h}$, respectively, for $12{ }^{\circ} \mathrm{C}$ fermentations and to 12,24 and $50 \mathrm{~h}$, respectively, for $20^{\circ} \mathrm{C}$ fermentations. Cells where centrifuged and stored at $80^{\circ} \mathrm{C}$. RNA isolation was performed with the High Pure RNA Isolation kit (Roche Applied Science, Germany). After oligo (dT) mRNA purification, RNAseq libraries were generated with the TruSeq Stranded mRNA Library Preparation Kit (Illumina, CA, USA). A pool of the libraries from the samples of the single $S$. cerevisiae T73 and S. kudriavzevii CR85 fermentations, and the S. cerevisiae T73 / S. kudriavzevii CR85 co-cultures was sequenced on a NextSeq Sequencing System from Illumina ( $2 \times 150 \mathrm{bp})$. Another pool including the single $S$. cerevisiae YPS128 culture and the S. cerevisiae YPS128 / S. kudriavzevii CR85 co-culture was also sequenced on a separate batch. All raw reads have been deposited under the BioProject PRJNA487511.

Pair end and read length sequencing allowed to effectively separate sequences coming from genomes with high identity. The large amount of reads that were generated in the process, granted obtaining enough data from the less represented transcriptomes in competitions.

\section{RNAseq and Differential Gene Expression Analysis}

Sequence reads from the S. cerevisiae T73 and S. kudriavzevii CR85 experiment were mapped to a combined reference of both genomes using Bowtie2 v. 2.2.9 (Langmead, 2013). Similarly, sequences from S. cerevisiae YPS128 and S. kudriavzevii CR85 experiment were mapped to a combined reference of those two genomes. The genomes of $S$. cerevisiae T73 and S. kudriavzevii CR85 were previously sequenced and annotated in our laboratory (M. Morard, unpublished ), and contained 6009 and 5537 genes, respectively, according to the 
RATT tool (Otto et al., 2011), refined by manual editing. Of them, 5414 genes were orthologous in both species. The reference genome sequence of S. cerevisiae YPS128 was obtained from Liti et. al (2009), but the annotation was revised in our laboratory. Read counts for each gene were obtained using HTSeq-Count (HTSeq-0.6.1p1, -m intersection-nonempty) (Anders et al., 2015). We obtained on average 13.5 million reads per strain and sample, with a range of 2.2 to 28.5 million after removing one expression outlier replicate of the sample $S$. cerevisiae T73 / S. kudriavzevii CR85, 12 C, EEP. We observed a median of 1034 reads per gene across all 118 samples.

Differential gene expression was estimated by using the R package DESeq2 (Love et al., 2014), based on fitting genes to a generalized linear model (GLM) to obtain maximumlikelihood estimates for the log fold changes (LFCs), to then acquire maximum a posteriori values from a second GLM round, which correspond to the final LFC values. Then, Wald tests were performed for differential expression by contrasting two groups, mono- vs. cocultures at each sampling time and temperature in most of the cases, as detailed in the Results section. Subsequently, Wald test p-values were adjusted for multiple testing, using the approach of Benjamini and Hochberg (1995). The resulting adjusted p-values were used as our reference p-values in the Results section.

Functional enrichment analyses were performed with the web tool FunSpec (Robinson et al., 2002), specially designed for yeast datasets. This tool calculates the probability that a Gene Ontology (GO) or Munich Information Centre for Protein Sequences (MIPS) term is enriched in a given list of genes using the hypergeometric distribution. A Bonferroni correction was applied to compensate the problem of multiple comparisons. 
575 For principal component analyses (PCA), a variance stabilizing transformation dataset from 576 the $\log _{2}$ fold scale normalized data given by DESeq 2 was used. This function, included in the

577 same R package, allows a more efficient clustering of samples into groups.

578 The expression matrix for heatmap building was obtained with the function

579 getVarianceStabilizedData from the DESeq2 package. Data was scaled to study the variation

580 of each gene in the given set of samples. The war.D clustering method for Euclidean distance

581 matrices was performed. We summarize the main biological processes with a reasonable

582 number of categories that included all the analysed genes.

\section{HPLC Analysis and data treatment}

584 Amino acids and ammonium were determined by High Performance Liquid Chromatography

585 (HPLC, Thermo Scientific Dioned ultimate 3000 series, Waltham, MA, USA). Separation

586 was made in a Thermo Scientific Accucore C18 column $(4.6 \mathrm{~mm} * 150 \mathrm{~mm}$ particle size

587 2.6um) following the method described in Gómez-Alonso et al. (2007).

588 Glucose and fructose concentrations along the fermentation were determined by HPLC

589 (Thermo Fisher Scientific, Waltham, MA, USA) using a refraction index detector and a

590 HyperREZTM XP Carbohydrate $\mathrm{H}+8 \mu \mathrm{m}$ column (Thermo Fisher Scientific) equipped with

591 a HyperREZTM XP Carbohydrate Guard (Thermo Fisher Scientific). Samples were

592 appropriately diluted, filtered through a $0.22-\mu \mathrm{m}$ nylon filter (Symta, Madrid, Spain), and

593 injected in two technical replicates. The analysis conditions were: eluent, $1.5 \mathrm{mM}$ of $\mathrm{H} 2 \mathrm{SO} 4$;

$5940.6 \mathrm{ml}$ min-1 flux and an oven temperature of $50{ }^{\circ} \mathrm{C}$.

595 Glucose and fructose utilization by yeasts during fermentation were fitted by means of the

596 three following mathematical equations as in (Tronchoni et al., 2009):

597 1. A linear decay function:

$$
Y=S_{0}-K * t
$$


Where $Y$ is the percentage of glucose or fructose still present in must, $t$ is the time (hours), $S_{0}$ is the value of interception in the origin, and $K$ is the kinetic constant.

2. An exponential decay function:

$$
Y=D+S * e^{-K * t}
$$

Where $Y$ is the percentage of glucose or fructose still present in must, $t$ is the time, $D$ is a specific value when $t$ tends to infinity, $S$ is the estimated value of change, and $K$ is the kinetic constant.

3. A sigmoid or altered Gompertz decay function:

$$
Y=A+C * e^{-e^{(K *(t-M))}}
$$

Where $Y$ is the percentage of glucose or fructose still present in must, $\mathrm{t}$ is the time, $A$ is the lower asymptote when $t$ tends to infinity, $K$ is the kinetic constant, $C$ is the distance between the upper and lower asymptote, and $M$ is the time when the inflection point is obtained.

Equations were fitted by means of linear and nonlinear regression procedures with the $\mathrm{R}$ function $n l s$ (R core team, 2018), minimizing the sum of squares of the difference between the experimental data and the fitted model. Fit adequacy was checked by the proportion of variance explained by the model $\left(\mathrm{R}^{2}\right)$ respect to the experimental data. For each yeast and temperature, the three equations were tested, but only the function with the highest $\mathrm{R}^{2}$ was chosen. Subsequently, these equations were used to calculate the time necessary to consume $90 \%$ of the initial sugar concentration present in must $(t 90)$.

\section{Compartmentalized fermentations}

Dialysis tubes (VISKING ${ }^{\circledR}$ dialysis tubing RC diameter $28 \mathrm{~mm}$, cut-off $\mathrm{MWCO}=12.000$ 14.000, SERVA Electrophoresis GmbH, Germany) were used to create an inner compartment 
623 of $20 \mathrm{~mL}$ of synthetic must located inside $250-\mathrm{mL}$ capacity screw cap bottles with $180 \mathrm{~mL}$ of

624 SM (outer compartment), as described elsewhere (Wang et al., 2015). This way, metabolite

625 and other solute can be exchanged between two yeast populations, inoculated and cultured in

626 the separated compartments. The different fermentation inoculation patterns are shown in

627 Table 4. Each compartment was inoculated to reach an initial concentration of $10^{6}$ cells $/ \mathrm{mL}$

628 of each strain. Bottles were incubated at $20^{\circ} \mathrm{C}$ and $100 \mathrm{rpm}$. Cell viability was measured by

629 plating into GPY-agar plates at different time points up to 60 hours of fermentation. After

630 that, cell deposition in the bottom of the membrane prevented us from obtaining decent

631 reproducibility among replicates. In the case of fermentations with both cell types in contact

632 in contact, two technical replicates were done; one of them incubated at a non-selective

633 temperature $\left(25^{\circ} \mathrm{C}\right)$, and the other at a selective temperature $\left(37^{\circ} \mathrm{C}\right)$ at which only $S$.

634 cerevisiae can grow. This way, selective temperature cultures can be used to determine the

635 CFU for S. cerevisiae, and subtracting this value from the total CFU obtained in the non-

636 selective plates, we can estimate CFU for S. kudriavzevii CR85.

637 To measure fitness, we calculated the intrinsic growth rate $(r)$ using the exponential growth 638 equation (Williams et al., 2015):

$$
N_{t}=N_{0} * e^{r * t}
$$

640 Where $N_{t}$ is final cell density $(\mathrm{CFU} / \mathrm{mL}), N_{0}$ is initial cell density $(\mathrm{CFU} / \mathrm{mL})$, and $t$ is time in

641 hours. Fermentation time 60 hours was used to estimate the intrinsic growth rate because it

642 showed the lowest deviation among replicates.

\section{Acknowledgements}

644 JAR was supported by a FPI grant from the Ministerio de Economia y Competitividad, Spain 
AGL2015-67504-C3-3-R from the Spanish Government and FEDER to AQ and EB,

respectively. RPT is supported by the aforementioned grant associated to AQ.

\section{References}

Albergaria, H., Francisco, D., Gori, K., Arneborg, N., and Gírio, F. (2010) Saccharomyces cerevisiae CCMI 885 secretes peptides that inhibit the growth of some nonSaccharomyces wine-related strains. Appl. Microbiol. Biotechnol. 86: 965-972.

Almeida, P., Barbosa, R., Zalar, P., Imanishi, Y., Shimizu, K., Turchetti, B., et al. (2015) A population genomics insight into the Mediterranean origins of wine yeast domestication. Mol. Ecol. 24: 5412-27.

Alonso-del-Real, J., Contreras-Ruiz, A., Castiglioni, G.L., Barrio, E., and Querol, A. (2017) The Use of Mixed Populations of Saccharomyces cerevisiae and S. kudriavzevii to Reduce Ethanol Content in Wine: Limited Aeration, Inoculum Proportions, and Sequential Inoculation. Front. Microbiol. 8:.

Alonso-del-Real, J., Lairón-Peris, M., Barrio, E., and Querol, A. (2017) Effect of Temperature on the Prevalence of Saccharomyces Non cerevisiae Species against a $S$. cerevisiae Wine Strain in Wine Fermentation: Competition, Physiological Fitness, and Influence in Final Wine Composition. Front. Microbiol. 8:.

Anders, S., Pyl, P.T., and Huber, W. (2015) HTSeq-A Python framework to work with highthroughput sequencing data. Bioinformatics 31: 166-169.

Andorrà, I., Berradre, M., Mas, A., Esteve-Zarzoso, B., and Guillamón, J.M. (2012) Effect of mixed culture fermentations on yeast populations and aroma profile. $L W T$ - Food Sci. Technol. 49: 8-13.

Arneborg, N., Siegumfeldt, H., Andersen, G.H., Nissen, P., Daria, V.R., Rodrigo, P.J., and Glückstad, J. (2005) Interactive optical trapping shows that confinement is a determinant of growth in a mixed yeast culture. FEMS Microbiol. Lett. 245: 155-159.

Arroyo-López, F.N., Pérez-Torrado, R., Querol, A., and Barrio, E. (2010) Modulation of the glycerol and ethanol syntheses in the yeast Saccharomyces kudriavzevii differs from that exhibited by Saccharomyces cerevisiae and their hybrid. Food Microbiol. 27: 628-637.

Arroyo-López, F.N., Pérez-Través, L., Querol, A., and Barrio, E. (2011) Exclusion of Saccharomyces kudriavzevii from a wine model system mediated by Saccharomyces cerevisiae. Yeast 28: 423-435.

Arroyo-López, F.N., Salvadó, Z., Tronchoni, J., Guillamón, J.M., Barrio, E., and Querol, A. (2010) Susceptibility and resistance to ethanol in Saccharomyces strains isolated from wild and fermentative environments. Yeast 27: 1005-1015.

Bagheri, B., Bauer, F.F., and Setati, M.E. (2016) The diversity and dynamics of indigenous yeast communities in grape must from vineyards employing different agronomic practices and their influence on wine fermentation. South African J. Enol. Vitic. 36:. 
Barbosa, C., García-Martínez, J., Pérez-Ortín, J.E., and Mendes-Ferreira, A. (2015) Comparative transcriptomic analysis reveals similarities and dissimilarities in Saccharomyces cerevisiae wine strains response to nitrogen availability. PLoS One 10:

Benjamini, Y. and Hochberg, Y. (1995) Controlling the False Discovery Rate: A Practical and Powerful Approach to Multiple Testing. J. R. Stat. Soc. Ser. B 57: 289-300.

Branco, P., Albergaria, H., Arneborg, N., and Prista, C. (2018) Effect of GAPDH-derived antimicrobial peptides on sensitive yeasts cells: membrane permeability, intracellular $\mathrm{pH}$ and $\mathrm{H}+$-influx/-efflux rates. FEMS Yeast Res.

Branco, P., Francisco, D., Chambon, C., Hébraud, M., Arneborg, N., Almeida, M.G., et al. (2014) Identification of novel GAPDH-derived antimicrobial peptides secreted by Saccharomyces cerevisiae and involved in wine microbial interactions. Appl. Microbiol. Biotechnol. 98: 843-853.

Branco, P., Francisco, D., Monteiro, M., Almeida, M.G., Caldeira, J., Arneborg, N., et al. (2016) Antimicrobial properties and death-inducing mechanisms of saccharomycin, a biocide secreted by Saccharomyces cerevisiae. Appl. Microbiol. Biotechnol. 101: 159171.

Carvalho-Netto, O. V, Carazzolle, M.F., Mofatto, L.S., Teixeira, P.J., Noronha, M.F., Calderón, L. AL, et al. (2015) Saccharomyces cerevisiae transcriptional reprograming due to bacterial contamination during industrial scale bioethanol production. Microb. Cell Fact. 14: 13.

Chen, G., Gharib, T.G., Huang, C.-C., Taylor, J.M.G., Misek, D.E., Kardia, S.L.R., et al. (2002) Discordant protein and mRNA expression in lung adenocarcinomas. Mol. Cell. Proteomics 1: 304-13.

Ciani, M., Capece, A., Comitini, F., Canonico, L., Siesto, G., and Romano, P. (2016) Yeast Interactions in Inoculated Wine Fermentation. Front. Microbiol. 7: 555.

Conant, G.C. and Wolfe, K.H. (2007) Increased glycolytic flux as an outcome of wholegenome duplication in yeast. Mol. Syst. Biol. 3: 129.

Crabtree, H.G. (1928) The carbohydrate metabolism of certain pathological overgrowths. Biochem. J. 22: 1289-98.

Curiel, J.A., Morales, P., Gonzalez, R., and Tronchoni, J. (2017) Different NonSaccharomyces Yeast Species Stimulate Nutrient Consumption in S. cerevisiae Mixed Cultures. Front. Microbiol. 8: 1-9.

Dong, Y., Hu, J., Fan, L., and Chen, Q. (2017) RNA-Seq-based transcriptomic and metabolomic analysis reveal stress responses and programmed cell death induced by acetic acid in Saccharomyces cerevisiae. Sci. Rep. 7: 1-16.

Fay, J.C. and Benavides, J.A. (2005) Evidence for Domesticated and Wild Populations of Saccharomyces cerevisiae. PLoS Genet. 1: e5.

Fleet, G.H. (2003) Yeast interactions and wine flavour. Int. J. Food Microbiol. 86: 11-22. 
Gamero, A., Tronchoni, J., Querol, A., and Belloch, C. (2013) Production of aroma compounds by cryotolerant Saccharomyces species and hybrids at low and moderate fermentation temperatures. J. Appl. Microbiol. 114: 1405-1414.

Gavrias, V., Andrianopoulos, A., Gimeno, C.J., and Timberlake, W.E. (1996) Saccharomyces cerevisiae TEC1 is required for pseudohyphal growth. Mol. Microbiol. 19: 1255-1263.

Ghazalpour, A., Bennett, B., Petyuk, V.A., Orozco, L., Hagopian, R., Mungrue, I.N., et al. (2011) Comparative Analysis of Proteome and Transcriptome Variation in Mouse. PLoS Genet. 7: e1001393.

Goddard, M.R. (2008) Quantifying the complexities of Saccharomyces cerevisiae's ecosystem engineering via fermentation. Ecology 89: 2077-2082.

Gómez-Alonso*, S., Hermosín-Gutiérrez, I., and García-Romero†, E. (2007) Simultaneous HPLC Analysis of Biogenic Amines, Amino Acids, and Ammonium Ion as Aminoenone Derivatives in Wine and Beer Samples. J. Agric. Food Chem 55: 608-613.

Goossens, K.V.Y., Ielasi, F.S., Nookaew, I., Stals, I., Alonso-Sarduy, L., Daenen, L., et al. (2015) Molecular mechanism of flocculation self-recognition in yeast and its role in mating and survival. MBio 6: e00427-15.

Gygi, S.P., Rochon, Y., Franza, B.R., and Aebersold, R. (1999) Correlation between protein and mRNA abundance in yeast. Mol. Cell. Biol. 19: 1720-30.

Hagman, A., Säll, T., Compagno, C., and Piskur, J. (2013) Yeast "Make-AccumulateConsume" Life Strategy Evolved as a Multi-Step Process That Predates the Whole Genome Duplication. PLoS One 8: e68734.

Hanlon, S.E., Rizzo, J.M., Tatomer, D.C., Lieb, J.D., Buck, M.J., and Lustig, A.J. (2011) The Stress Response Factors Yap6, Cin5, Phd1, and Skn 7 Direct Targeting of the Conserved Co-Repressor Tup1-Ssn6 in S. cerevisiae.

Henderson, K.A., Hughes, A.L., and Gottschling, D.E. (2014) Mother-daughter asymmetry of $\mathrm{pH}$ underlies aging and rejuvenation in yeast. Elife 3:.

Henriques, D., Alonso-del-Real, J., Querol, A., and Balsa-Canto, E. (2018) Saccharomyces cerevisiae and S. kudriavzevii Synthetic Wine Fermentation Performance Dissected by Predictive Modeling. Front. Microbiol. 9: 88.

Jolly, N.P., Varela, C., and Pretorius, I.S. (2014) Not your ordinary yeast: NonSaccharomyces yeasts in wine production uncovered. FEMS Yeast Res. 14: 215-237.

Kemsawasd, V., Branco, P., Almeida, M.G., Caldeira, J., Albergaria, H., and Arneborg, N. (2015) Cell-to-cell contact and antimicrobial peptides play a combined role in the death of Lachanchea thermotolerans during mixed-culture alcoholic fermentation with Saccharomyces cerevisiae. FEMS Microbiol. Lett. 362: 1-8.

Langmead (2013) Fast gapped-read alignment with Bowtie 2. 9: 357-359.

Liti, G., Carter, D.M., Moses, A.M., Warringer, J., Parts, L., James, S.A., et al. (2009) Population genomics of domestic and wild yeasts. Nature 458: 337-41. 
Love, M.I., Huber, W., and Anders, S. (2014) Moderated estimation of fold change and dispersion for RNA-seq data with DESeq2. Genome Biol. 15: 550.

De Maeyer, D., Weytjens, B., Renkens, J., De Raedt, L., and Marchal, K. (2015) PheNetic: Network-based interpretation of molecular profiling data. Nucleic Acids Res. 43: W244W250.

Marsit, S. and Dequin, S. (2015) Diversity and adaptive evolution of Saccharomyces wine yeast: a review. FEMS Yeast Res. 15: fov067.

Marsit, S., Sanchez, I., Galeote, V., and Dequin, S. (2016) Horizontally acquired oligopeptide transporters favour adaptation of Saccharomyces cerevisiae wine yeast to oenological environment. Environ. Microbiol. 18: 1148-1161.

Mendes, I., Sanchez, I., Franco-Duarte, R., Camarasa, C., Schuller, D., Dequin, S., and Sousa, M.J. (2017) Integrating transcriptomics and metabolomics for the analysis of the aroma profiles of Saccharomyces cerevisiae strains from diverse origins. BMC Genomics 18: 455.

Mendizabal, I., Rios, G., Mulet, J.M., Serrano, R., and de Larrinoa, I.F. (1998) Yeast putative transcription factors involved in salt tolerance. FEBS Lett. 425: 323-328.

Merico, A., Sulo, P., Piškur, J., and Compagno, C. (2007) Fermentative lifestyle in yeasts belonging to the Saccharomyces complex. FEBS J. 274: 976-989.

Monteiro, F.F.. and Bisson, L.F. (1991) Biological Assay of Nitrogen Content of Grape Juice and Prediction of Sluggish Fermentations American Society of Enologists.

Navarro-Tapia, E., Nana, R.K., Querol, A., and Pérez-Torrado, R. (2016) Ethanol Cellular Defense Induce Unfolded Protein Response in Yeast. Front. Microbiol. 7:.

Nevitt, T., Pereira, J., and Rodrigues-Pousada, C. (2004) YAP4 gene expression is induced in response to several forms of stress in Saccharomyces cerevisiae. Yeast 21: 1365-1374.

Nielsen, J.C., Senne de Oliveira Lino, F., Rasmussen, T.G., Thykær, J., Workman, C.T., and Basso, T.O. (2017) Industrial antifoam agents impair ethanol fermentation and induce stress responses in yeast cells. Appl. Microbiol. Biotechnol. 101: 8237-8248.

Nissen, P. and Arneborg, N. (2003) Characterization of early deaths of non-Saccharomyces yeasts in mixed cultures with Saccharomyces cerevisiae. Arch. Microbiol. 180: 257-263.

Novo, M., Mangado, A., Quirós, M., Morales, P., Salvadó, Z., and Gonzalez, R. (2013) Genome-wide study of the adaptation of Saccharomyces cerevisiae to the early stages of wine fermentation. PLoS One 8: e74086.

Otto, T.D., Dillon, G.P., Degrave, W.S., and Berriman, M. (2011) RATT: Rapid Annotation Transfer Tool. Nucleic Acids Res. 39: e57.

Pan, X. and Heitman, J. (2000) Sok2 regulates yeast pseudohyphal differentiation via a transcription factor cascade that regulates cell-cell adhesion. Mol. Cell. Biol. 20: 836472. 
Pascal, L.E., True, L.D., Campbell, D.S., Deutsch, E.W., Risk, M., Coleman, I.M., et al. (2008) Correlation of mRNA and protein levels: cell type-specific gene expression of cluster designation antigens in the prostate. BMC Genomics 9: 246.

Pérez-Nevado, F., Albergaria, H., Hogg, T., and Girio, F. (2006) Cellular death of two nonSaccharomyces wine-related yeasts during mixed fermentations with Saccharomyces cerevisiae. Int. J. Food Microbiol. 108: 336-45.

Pérez-Ortín, J.E., Querol, A., Puig, S., and Barrio, E. (2002) Molecular characterization of a chromosomal rearrangement involved in the adaptive evolution of yeast strains. Genome Res. 12: 1533-9.

Pérez-Torrado, R., Barrio, E., and Querol, A. (2017) Alternative yeasts for winemaking: Saccharomyces non- cerevisiae and its hybrids. Crit. Rev. Food Sci. Nutr. 31: 1-11.

Pérez-Torrado, R., Rantsiou, K., Perrone, B., Navarro-Tapia, E., Querol, A., and Cocolin, L. (2017) Ecological interactions among Saccharomyces cerevisiae strains: insight into the dominance phenomenon. Sci. Rep. 7: 43603.

Peris, D., Pérez-Través, L., Belloch, C., and Querol, A. (2016) Enological characterization of Spanish Saccharomyces kudriavzevii strains, one of the closest relatives to parental strains of winemaking and brewing Saccharomyces cerevisiae x S. kudriavzevii hybrids. Food Microbiol. 53: 31-40.

Perrone, B., Giacosa, S., Rolle, L., Cocolin, L., and Rantsiou, K. (2013) Investigation of the dominance behavior of Saccharomyces cerevisiae strains during wine fermentation. Int. J. Food Microbiol. 165: 156-162.

Peter, J., De Chiara, M., Friedrich, A., Yue, J.-X., Pflieger, D., Bergstrom, A., et al. (2018) Genome evolution across 1,011 Saccharomyces cerevisiae isolates. Nat.

Piskur, J. and Langkjaer, R.B. (2004) Yeast genome sequencing: the power of comparative genomics. Mol. Microbiol. 53: 381-9.

Piškur, J., Rozpedowska, E., Polakova, S., Merico, A., and Compagno, C. (2006) How did Saccharomyces evolve to become a good brewer? Trends Genet. 22: 183-186.

Querol, A., Barrio, E., and Ramón, D. (1994) Population dynamics of natural Saccharomyces strains during wine fermentation. Int. J. Food Microbiol. 21: 315-23.

Querol, A., Fernández-Espinar, M.T., del Olmo, M. lí, and Barrio, E. (2003) Adaptive evolution of wine yeast. Int. J. Food Microbiol. 86: 3-10.

Querol, A., Huerta, T., Barrio, E., and Ramon, D. (1992) Dry Yeast Strain For Use in Fermentation of Alicante Wines: Selection and DNA Patterns. J. Food Sci. 57: 183-185.

R Core Team (2018) R: A language and environment for statistical computing. R Foundation for Statistical Computing, Vienna, Austria.

Renault, P.E., Albertin, W., and Bely, M. (2013) An innovative tool reveals interaction mechanisms among yeast populations under oenological conditions. Appl. Microbiol. Biotechnol. 97: 4105-4119. 
Rivero, D., Berná, L., Stefanini, I., Baruffini, E., Bergerat, A., Csikász-Nagy, A., et al. (2015) Hsp12p and $P A U$ genes are involved in ecological interactions between natural yeast strains. Environ. Microbiol. 17: 3069-3081.

Robinson, M.D., Grigull, J., Mohammad, N., and Hughes, T.R. (2002) FunSpec: a web-based cluster interpreter for yeast. 3: 35 .

Rossignol, T., Dulau, L., Julien, A., and Blondin, B. (2003) Genome-wide monitoring of wine yeast gene expression during alcoholic fermentation. Yeast 20: 1369-1385.

Rossouw, D., Bagheri, B., Setati, M.E., and Bauer, F.F. (2015) Co-Flocculation of Yeast Species, a New Mechanism to Govern Population Dynamics in Microbial Ecosystems. PLoS One 10: e0136249.

Rossouw, D., Du Toit, M., and Bauer, F.F. (2012) The impact of co-inoculation with Oenococcus oeni on the trancriptome of Saccharomyces cerevisiae and on the flavouractive metabolite profiles during fermentation in synthetic must. Food Microbiol. 29: 121-131.

Sardi, M., Rovinskiy, N., Zhang, Y., and Gasch, A.P. (2016) Leveraging Genetic-Background Effects in Saccharomyces cerevisiae To Improve Lignocellulosic Hydrolysate Tolerance. Appl. Environ. Microbiol. 82: 5838-49.

Sniegowski, P.D., Dombrowski, P.G., and Fingerman, E. (2002) Saccharomyces cerevisiae and Saccharomyces paradoxus coexist in a natural woodland site in North America and display different levels of reproductive isolation from European conspecifics. FEMS Yeast Res. 1: 299-306.

Sollner, S., Schober, M., Wagner, A., Prem, A., Lorkova, L., Palfey, B.A., et al. (2009) Quinone reductase acts as a redox switch of the $20 \mathrm{~S}$ yeast proteasome. EMBO Rep. 10: $65-70$.

Stribny, J., Gamero, A., Pérez-Torrado, R., and Querol, A. (2015) Saccharomyces kudriavzevii and Saccharomyces uvarum differ from Saccharomyces cerevisiae during the production of aroma-active higher alcohols and acetate esters using their amino acidic precursors. Int. J. Food Microbiol. 205: 41-6.

Stribny, J., Romagnoli, G., Pérez-Torrado, R., Daran, J.-M., and Querol, A. (2016) Characterisation of the broad substrate specificity 2-keto acid decarboxylase Aro $10 \mathrm{p}$ of Saccharomyces kudriavzevii and its implication in aroma development. Microb. Cell Fact. 15: 51.

Tronchoni, J., Curiel, J.A., Morales, P., Torres-Pérez, R., and Gonzalez, R. (2017) Early transcriptional response to biotic stress in mixed starter fermentations involving Saccharomyces cerevisiae and Torulaspora delbrueckii. Int. J. Food Microbiol. 241: 6068.

Tronchoni, J., Gamero, A., Arroyo-López, F.N., Barrio, E., and Querol, A. (2009) Differences in the glucose and fructose consumption profiles in diverse Saccharomyces wine species and their hybrids during grape juice fermentation. Int. J. Food Microbiol. 134: 237-43. 
Tronchoni, J., Medina, V., Guillamón, J.M., Querol, A., and Pérez-Torrado, R. (2014) Transcriptomics of cryophilic Saccharomyces kudriavzevii reveals the key role of gene translation efficiency in cold stress adaptations. BMC Genomics 15: 432.

Varela, C., Sengler, F., Solomon, M., and Curtin, C. (2016) Volatile flavour profile of reduced alcohol wines fermented with the non-conventional yeast species Metschnikowia pulcherrima and Saccharomyces uvarum. Food Chem. 209: 57-64.

Wang, C., Mas, A., and Esteve-Zarzoso, B. (2015) Interaction between Hanseniaspora uvarum and Saccharomyces cerevisiae during alcoholic fermentation. Int. J. Food Microbiol. 206: 67-74.

Williams, K.M., Liu, P., and Fay, J.C. (2015) Evolution of ecological dominance of yeast species in high-sugar environments. Evolution 69: 2079-93.

Yang, J.-R., Maclean, C.J., Park, C., Zhao, H., and Zhang, J. (2017) Intra and Interspecific Variations of Gene Expression Levels in Yeast Are Largely Neutral: (Nei Lecture, SMBE 2016, Gold Coast). Mol. Biol. Evol. 34: 2125-2139.

Yeung, E.S. (2011) Genome-wide correlation between mRNA and protein in a single cell. Angew. Chem. Int. Ed. Engl. 50: 583-5.

Zhang, W., Li, Y., Chen, Y., Xu, S., Du, G., Shi, H., et al. (2018) Complete genome sequence and analysis of the industrial Saccharomyces cerevisiae strain N85 used in Chinese rice wine production. DNA Res. 25: 297.

Zimmer, A., Durand, C., Loira, N., Durrens, P., Sherman, D.J., and Marullo, P. (2014) QTL Dissection of Lag Phase in Wine Fermentation Reveals a New Translocation Responsible for Saccharomyces cerevisiae Adaptation to Sulfite. PLoS One 9: e86298.

Zuzuarregui, A., Monteoliva, L., Gil, C., and del Olmo, M. lí (2006) Transcriptomic and proteomic approach for understanding the molecular basis of adaptation of Saccharomyces cerevisiae to wine fermentation. Appl. Environ. Microbiol. 72: 836-47. 
Table 1. Summary of the main GO terms and genes differentially expressed by $\boldsymbol{S}$. kudriavzevii CR85 in competition with $S$. cerevisiae $\mathrm{T} 73$

\begin{tabular}{|c|c|c|c|}
\hline & & $12^{\circ} \mathrm{C}$ & $20^{\circ} \mathrm{C}$ \\
\hline \multirow[t]{2}{*}{ EEP } & $\mathbf{U P}$ & $\begin{array}{l}\text { sexual reproduction (SPS18, } \\
\text { FUS2, GAT3, CCH1, DON1, } \\
\text { MSH5, 322YSW1), stress response } \\
\text { (RSB1, FAA1, SLH1, FRT2), } \\
\text { nutrient homeostasis and transport } \\
\text { (IZH4, MLS1, HFA1, FAT3, } \\
\text { TRK1, YIL166C, SUC2, PUS6, } \\
\text { ZRT1, AGX1, ARG5, MPH2, } \\
\text { HXT2) }\end{array}$ & $\begin{array}{l}\text { structural constituen of cell wall, } \\
\text { plasma membrane, regulation of C- } \\
\text { compound and carbohydrate, stress } \\
\text { response, sugar transport, } \\
\text { pseudohyphal growth and sporulation } \\
\text { (STE7, GPA2, DFG5, PTP2), } \\
\text { methionine transport and synthesis } \\
\text { genes (MUP3, MET6, SAM3), iron } \\
\text { ion uptake and homeostasis }(F R E 3 \text {, } \\
\text { FIT2, FIT3, TIR1, TIR3, FET4), and } \\
\text { aroma synthesis }(A T F 1, A R O 10)\end{array}$ \\
\hline & DOWN & glucose catabolism, & translation, cell cycle \\
\hline \multirow[t]{2}{*}{ LEP } & $\mathbf{U P}$ & \multicolumn{2}{|c|}{$\begin{array}{l}\text { Ergosterol biosynthetic process, aerobic respiration, integral to membrane } \\
\text { response, membrane oxidative stress, sporulation or pseudohyphal growth } \\
(I M E 1, R I M 4, R I M 11, S P O 24, M S C 7, Y N L 194 C, S L Z 1, A D Y 2, F M P 45 \text {, } \\
D I G 2, H Y P 2, R C K 1, A Q Y 1) \text {, nutrient limitation (GIS1, ADR1, SIP2, } \\
M R S 4, I C Y 1, P U T 1, H M X 1, H X T 2, H X T 7 \text { and } G A L 11) \text {, response to drugs } \\
(P M P 3, P D R 1, Y O R 1, F Y V 4, P D R 5, C I N 5) \text {, aromatic compounds } \\
\text { synthesis (ARO80), general stress response (MSN4) }\end{array}$} \\
\hline & DOWN & nucleotide binding & \\
\hline \multirow[t]{2}{*}{ SP } & UP & $\begin{array}{l}\text { ribosome biosynthesis, } \\
\text { transcription, DNA-dependent, } \\
\text { metal ion binding, ergosterol } \\
\text { biosynthesis process, iron ion } \\
\text { homeosthasis, sequence specific } \\
\text { DNA binding }\end{array}$ & $\begin{array}{l}\text { methionine biosynthesis process, } \\
\text { transmembrane transport, oxidation- } \\
\text { reduction process, sulfate } \\
\text { assimilation, cysteine biosynthesis } \\
\text { process, iron ion homeosthasis, zinc } \\
\text { ion binding, fatty acid metabolic } \\
\text { process, ergosterol biosynthetic } \\
\text { process, sequence specific DNA } \\
\text { binding }\end{array}$ \\
\hline & DOWN & $\begin{array}{l}\text { mitocondrial translation, } \\
\text { proteolysis, oxidative stress } \\
\text { respirtation, trehalose biosynthetic } \\
\text { process and protein refolding }\end{array}$ & $\begin{array}{l}\text { translation, mitosis, mitochondrial } \\
\text { translation, proteasomal ubiquitin- } \\
\text { independent, trehalose biosynthetic } \\
\text { process and protein refolding }\end{array}$ \\
\hline
\end{tabular}


905

906

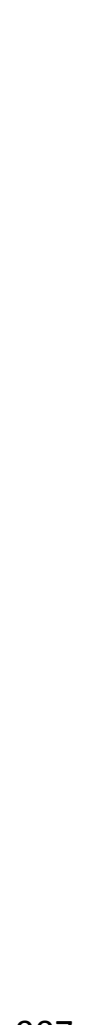

908

Table 2. Summary of nodal transcriptions factors in gene interaction networks obtained with Phenetics

\begin{tabular}{|c|c|c|c|c|}
\hline & Temperature & EEP & LEP & SP \\
\hline \multirow{2}{*}{$\begin{array}{l}S . \\
\text { cerevisiae }\end{array}$} & $12{ }^{\circ} \mathrm{C}$ & $\begin{array}{l}\text { Cin5p, Mgalp, } \\
\text { Msn4p, Phd1p, } \\
\text { Swi5p, Tos8p }\end{array}$ & $\begin{array}{l}\text { Cin5p, Hmo1p, } \\
\text { Msn4p, Ste12p, } \\
\text { Sip4p, Tos } 8 p, \\
\text { Yox1p, }\end{array}$ & $\begin{array}{l}\text { Met } 28 p, \text { Met32p, } \\
\text { Tec1p, Thi2p, } \\
\text { Tos8p, Sok } 2 p\end{array}$ \\
\hline & $20{ }^{\circ} \mathrm{C}$ & $\begin{array}{l}\text { Aft1p, Hap1p, } \\
\text { Mga2p, Msn2p, } \\
\text { Msn4p, Phd1p, } \\
\text { Spt23p, Tye7p, } \\
\text { Ume5p }\end{array}$ & & \\
\hline \multirow[t]{2}{*}{$\begin{array}{l}\text { S. } \\
\text { kudriavzevii }\end{array}$} & $12{ }^{\circ} \mathrm{C}$ & & $\begin{array}{l}\text { Adr1p, Cin5p, } \\
\text { Hap1p, Met32p, } \\
\text { Mga1p, Phd1p, } \\
\text { Sok2p, Yap5p }\end{array}$ & $\begin{array}{l}\text { Cin5p, Hap4p, } \\
\text { Met32p, Mga1p, } \\
\text { Msn4p, Phd1p, } \\
\text { Ste12p, Sok2p, } \\
\text { Tos8p, Yap6p }\end{array}$ \\
\hline & $20{ }^{\circ} \mathrm{C}$ & $\begin{array}{l}\text { Cin5p, Hap1p, } \\
\text { Hap4p, Mga1p, } \\
\text { Msn4p, Sok2p }\end{array}$ & $\begin{array}{l}\text { Cin5p, Msn4p, } \\
\text { Nrg1p, Sip4p, } \\
\text { Sok2p, Swi5p }\end{array}$ & $\begin{array}{l}\text { Cin5p, Mig1p, } \\
\text { Phd1p, Sok2p, } \\
\text { Yap5p, Yap6p }\end{array}$ \\
\hline
\end{tabular}


909 Table 3. Time (h) to consume $90 \%$ of glucose and fructose initially present in the media

910 (t90). Values are given as mean \pm standard deviation of three biological replicates and two 911 HPLC detection runs. An ANOVA analysis was carried out.

\begin{tabular}{|c|c|c|c|c|c|c|}
\hline Temperature & Sugar & t90 T73 & t90 YPS128 & t90 CR85 & $\mathrm{t}^{90_{\mathrm{T} 73-\mathrm{CR} 85}}$ & $\begin{array}{l}\text { t90 YPS128- } \\
\text { CR85 }\end{array}$ \\
\hline \multirow{2}{*}{$12^{\circ} \mathrm{C}$} & Glucose & $\begin{array}{l}371.1 \pm \\
10.3^{b}\end{array}$ & $\begin{array}{l}382.6 \pm \\
20.1^{b}\end{array}$ & $\begin{array}{l}316.0 \pm \\
4.0^{\mathrm{a}, \mathrm{b}}\end{array}$ & $\begin{array}{l}255.2 \pm \\
61.2^{\mathrm{a}}\end{array}$ & $\begin{array}{l}361.0 \pm \\
12.7^{\mathrm{b}}\end{array}$ \\
\hline & Fructose & $\begin{array}{l}601.1 \pm \\
11.9^{c}\end{array}$ & $\begin{array}{l}623.5 \pm \\
16.6^{c}\end{array}$ & $\begin{array}{l}486.0 \pm \\
59.1^{\mathrm{b}}\end{array}$ & $\begin{array}{l}346.3 \pm \\
70.5^{\mathrm{a}}\end{array}$ & $\begin{array}{l}548.6 \pm \\
8.4^{\mathrm{b}, \mathrm{c}}\end{array}$ \\
\hline \multirow{2}{*}{$20{ }^{\circ} \mathrm{C}$} & Glucose & $\begin{array}{l}214.6 \pm \\
16.2^{a}\end{array}$ & $\begin{array}{l}191.4 \pm \\
8.1^{\mathrm{a}}\end{array}$ & $\begin{array}{l}280.1 \pm \\
0.9^{b}\end{array}$ & $220.1 \pm 4.5^{\mathrm{a}}$ & $\begin{array}{l}211.9 \pm \\
23.5^{\mathrm{a}}\end{array}$ \\
\hline & Fructose & $\begin{array}{l}368.5 \pm \\
13.2^{\mathrm{a}, \mathrm{b}}\end{array}$ & $\begin{array}{l}342.9 \pm \\
10.9^{a}\end{array}$ & $\begin{array}{l}446.0 \pm \\
8.0^{c}\end{array}$ & $\begin{array}{l}387.7 \pm \\
14.0^{\mathrm{b}}\end{array}$ & $\begin{array}{l}339.8 \pm \\
25.0^{\mathrm{a}}\end{array}$ \\
\hline
\end{tabular}

913 The values followed by different superindexes in the same row are significantly different

914 according to the Tukey HSD test $(\alpha=0.05)$. 
918 Table 4. Summary of compartmentalized fermentations performed.

\begin{tabular}{l|lll|llll|lc}
\hline \multicolumn{9}{c}{ MONOCULTURE } & \multicolumn{3}{c}{ SEPARATED } & IN CONTACT \\
\hline $\begin{array}{l}\text { Inner } \\
\text { compartment }\end{array}$ & ScT73 & ScYPS128 & SkCR85 & ScT73 & SkCR85 & ScYPS128 & SkCR85 & ScT73, SkCR85 & $\begin{array}{l}\text { ScYPS128, } \\
\text { SkCR85 }\end{array}$ \\
\hline $\begin{array}{l}\text { Outer } \\
\text { compartment }\end{array}$ & ScT73 & ScYPS128 & SkCR85 & SkCR85 & ScT73 & SkCR85 & ScYPS128 & ScT73, SkCR85 & $\begin{array}{l}\text { ScYPS128, } \\
\text { SkCR85 }\end{array}$ \\
\hline
\end{tabular}




\section{Fig 1. Principal component analysis of differential gene expression for $S$. cerevisiae and} S. kudriavzevii

Fig 2. (A) Number of differentially expressed genes in competition for each species at every temperature and phase of fermentation. (B) Growth curves of single (continuous curves) and mixed cultures (dashed curves) at $20^{\circ} \mathrm{C}$. Samples were taken at $15 \mathrm{~h}, 24 \mathrm{~h}, 39 \mathrm{~h}$ and $60 \mathrm{~h}$. Values are mean of three to six replicates. Error bars represent standard deviation.

Fig 3. (A) Hierarchical clustering of culture-dependent genes during EEP divided into functional categories. (B) Genetic interactions of culture-dependent genes given by Phenetics (network size $=100)$. $(\mathbf{C})$ Expression profile (Norm. expr.) of genes MIP1 and HSP30. Variance stabilizing transformation of the dispersion estimates dataset was used to reduce dependence of the variance on the mean.

Fig 4. Increment of percentage of consumption of different nitrogen compounds between 24 hours and 12 hours in fermentation at $20^{\circ} \mathrm{C}$. Values are the mean of three replicates. Error bars represent standard deviations. ANOVA analysis and Tuckey test were performed for significance evaluation $(*=\mathrm{p}$-value $<0.05, * *=\mathrm{p}$-value $<0.01)$.

Fig 5. Sugars consumption profiles during fermentations with single cultures of $S$. cerevisiae and $\boldsymbol{S}$. kudriavzevii and co-cultures. Curves are the representation of sugars concentrations data fitted to different models (R2>0.9).

Fig 6. Fitness after 60 hours in compartmentalized fermentations. Intrinsic growth rate (r) was calculated for inner and outer compartment in fermentations with only one of the yeast in both compartments (Sc_mono and $S k \_$mono), the two yeast separated in different compartments (Sc_co_no.contact and $\left.S k \_c o \_n o . c o n t a c t\right)$, and the two yeast mixed in both compartments (Sc_co_contact and $\left.S k \_c o \_c o n t a c t\right)$. Values are mean of six replicates (both from inner and outer compartment taken together), and error bars represent standard deviation. ANOVA analysis and Tuckey test were performed for significance evaluation (** $=\mathrm{p}$-value $<0.01, * * *=\mathrm{p}$-value $<0.001)$.

Fig 7. (A) Number of differentially expressed genes in competition. (B) Growth curves of single $(S c, S k)$ and mixed cultures $\left(S c \_c o, S k \_c o\right)$ at $20^{\circ} \mathrm{C}$. Samples were taken at $15 \mathrm{~h}, 24 \mathrm{~h}$, $39 \mathrm{~h}$ and $60 \mathrm{~h}$. Values are mean of three to six replicates. Error bars represent standard deviation.

Fig 8. Fitness after 60 hours in compartmentalized fermentations. Intrinsic growth rate $(r)$ was calculated for inner and outer compartment in fermentations with only one of the yeast in both compartments (Sc_mono and $\left.S k \_m o n o\right)$, the two yeast separated in different compartments (Sc_co_no.contact and $\left.S k \_c o \_n o . c o n t a c t\right)$, and the two yeast mixed in both compartments (Sc_co_contact and Sk_co_contact). Values are mean of six replicates (both from inner and outer compartment taken together), and error bars represent standard deviation. An ANOVA analysis and a Tuckey test were performed for significance evaluation; however, differences were not significant in any comparison. 


\section{Page 41 of 52}

\section{0}


Table S1: Enriched functional terms obtained from the differentially expressed genes of

S. cerevisiae T73 at EEP during competition

Table S2: Differentially expressed genes of $S$. cerevisiae T73 during competition

965

966

Table S3: Differentially expressed genes of $S$. kudriavzevii CR85 during competition with S. cerevisiae $\mathrm{T} 73$

Table S4: Differentially expressed genes of $S$. cerevisiae YPS128 during competition

Table S5: Enriched functional terms obtained from the differentially expressed genes of S. kudriavzevii CR85 at EEP during competition with $S$. cerevisiae YPS128

Table S6: Differentially expressed genes of S. kudriavzevii CR85 at EEP during competition with $S$. cerevisiae YPS128

Figure S1: Growth curves of S. cerevisiae T73 and S. kudriavzevii throughout all the fermentation at $12{ }^{\circ} \mathrm{C}$ and $20^{\circ} \mathrm{C}$. Cell number was measured by cell counting. Values are mean of three replicates.

Fifure S2: Principal component analysis of differential gene expression for $S$. cerevisiae and $S$. kudriavzevii

Figure S3: Hierarchical clustering of genes affected by the variable culture. Euclidean distance matrix obtained from the expression matrix was used for clustering with ward.D method.

Figure S4: Percentage of consumption of different nitrogen compounds at 8 hours (A) 
981 and 24 hours $(B)$ in fermentation at $20^{\circ} \mathbf{C}$. Values are the mean of three replicates. Error 982 bars represent standard deviations. 


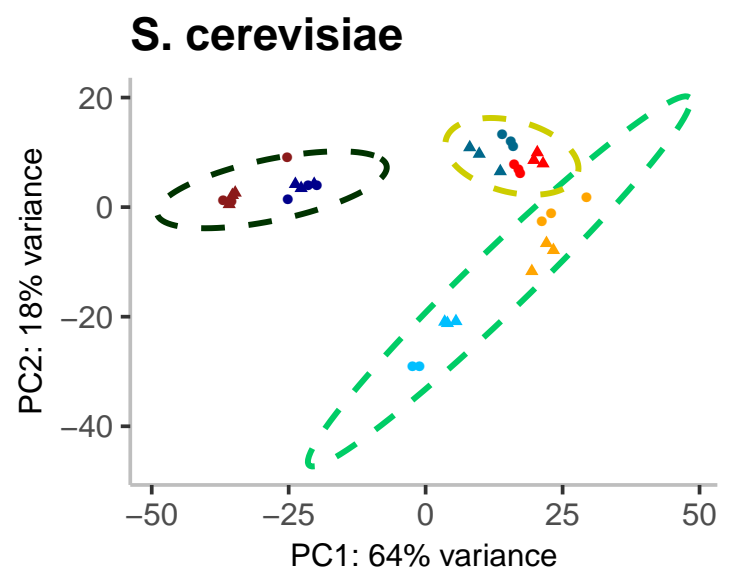

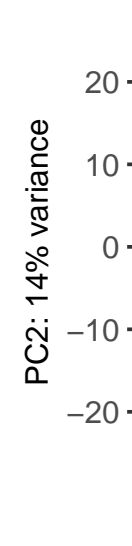

S. kudriavzevii
- $\operatorname{EEP}\left(20^{\circ} \mathrm{C}\right)$

- $\quad \operatorname{LEP}\left(20^{\circ} \mathrm{C}\right)$

- $\quad \mathrm{SP}\left(20^{\circ} \mathrm{C}\right)$

- $\operatorname{EEP}\left(12^{\circ} \mathrm{C}\right)$

- $\quad \operatorname{LEP}\left(12^{\circ} \mathrm{C}\right)$

- $\quad \mathrm{SP}\left(12^{\circ} \mathrm{C}\right)$

Fermentation stage

- EEP

- LEP

- $\quad \mathrm{Sp}$

Culture

- co

- mono 


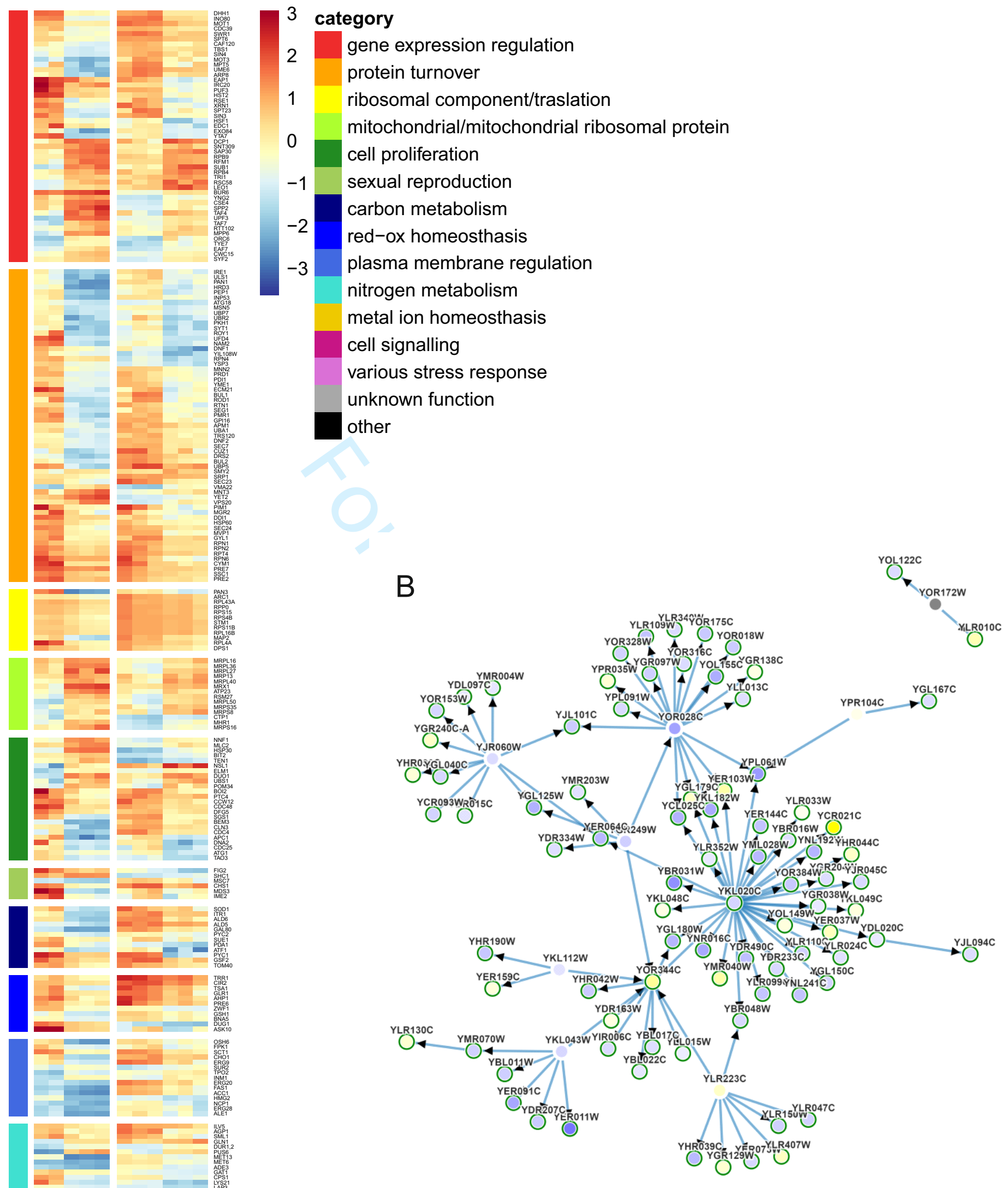

C

YOR328W - MIP1
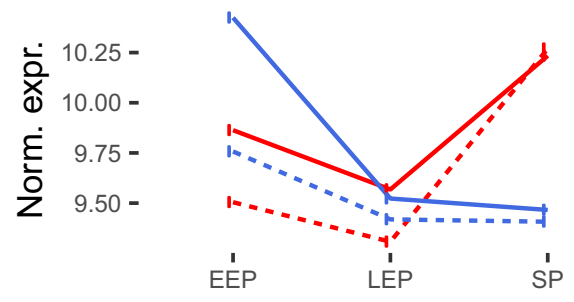

Wiley-Blackwell and Sime Society for Applied Microbiology
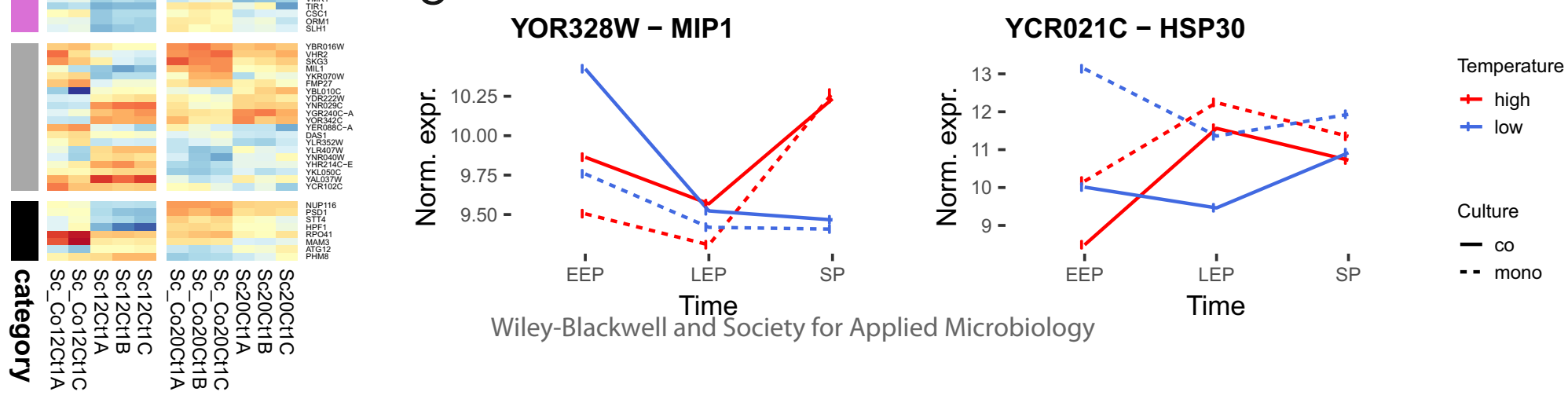


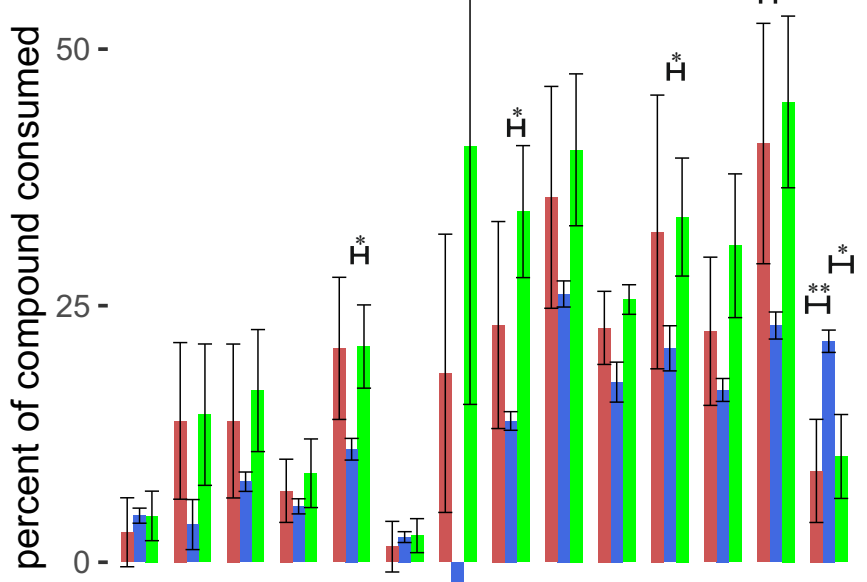

culture

S. cerevisiae T73

S. kudriavzevii CR85 Mixed culture

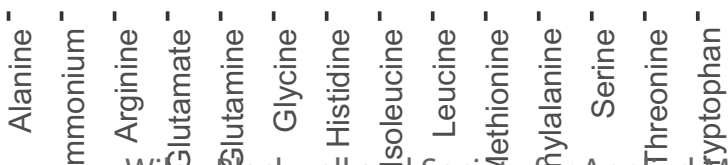

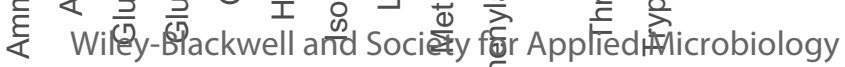




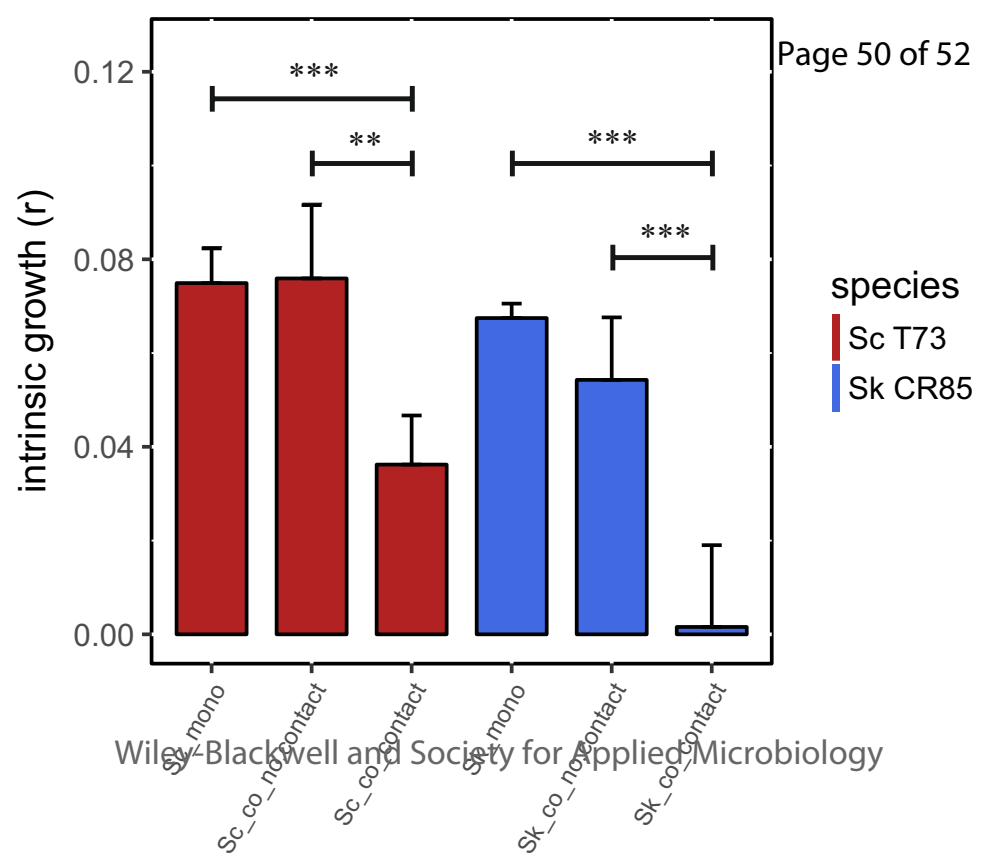




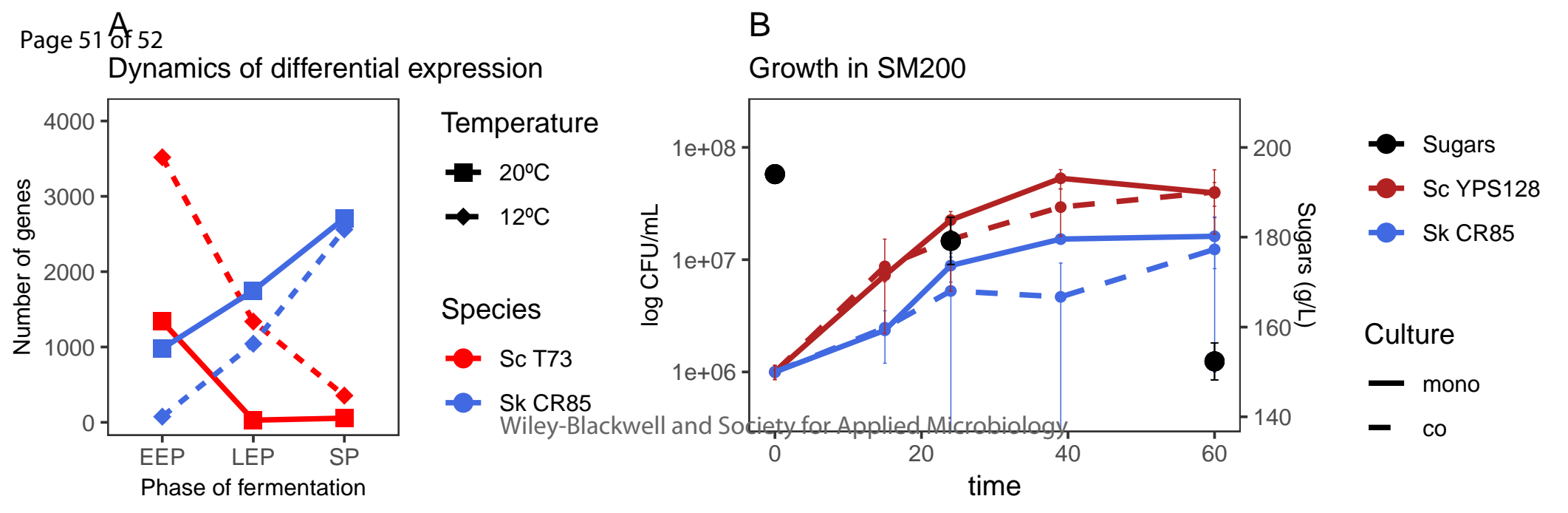




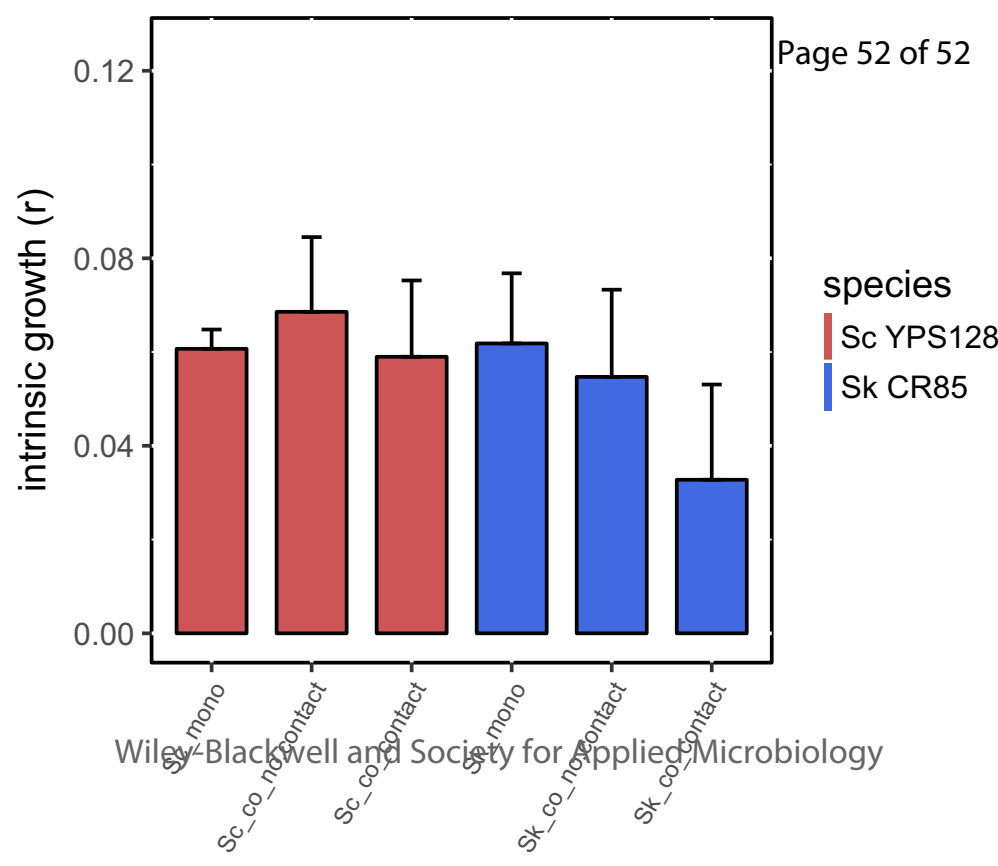

